\title{
Identification of Different Putative Outer Membrane Electron Conduits Necessary for Fe(III) Citrate, Fe(III) Oxide, Mn(IV) Oxide, or Electrode Reduction by Geobacter sulfurreducens
}

\author{
(D) Fernanda Jiménez Otero, ${ }^{a, b}$ (D) Chi Ho Chan, Daniel R. Bonda,c \\ aBioTechnology Institute, University of Minnesota_-Twin Cities, St. Paul, Minnesota, USA \\ bepartment of Biochemistry, Molecular Biology, and Biophysics, University of Minnesota-Twin Cities, St. \\ Paul, Minnesota, USA \\ cDepartment of Plant and Microbial Biology, University of Minnesota_-Twin Cities, St. Paul, Minnesota, USA
}

ABSTRACT At least five gene clusters in the Geobacter sulfurreducens genome encode putative "electron conduits" implicated in electron transfer across the outer membrane, each containing a periplasmic multiheme c-type cytochrome, integral outer membrane anchor, and outer membrane redox lipoprotein(s). Markerless single-gene-cluster deletions and all possible multiple-deletion combinations were constructed and grown with soluble $\mathrm{Fe}(\mathrm{III})$ citrate, Fe(III) and $\mathrm{Mn}$ (IV) oxides, and graphite electrodes poised at $+0.24 \mathrm{~V}$ and $-0.1 \mathrm{~V}$ versus the standard hydrogen electrode (SHE). Different gene clusters were necessary for reduction of each electron acceptor. During metal oxide reduction, deletion of the previously described omcBC cluster caused defects, but deletion of additional components in an $\triangle o m c B C$ background, such as extEFG, were needed to produce defects greater than $50 \%$ compared to findings with the wild type. Deletion of all five gene clusters abolished all metal reduction. During electrode reduction, only the $\triangle \operatorname{ext} A B C D$ mutant had a severe growth defect at both redox potentials, while this mutation did not affect Fe(III) oxide, $\mathrm{Mn}(\mathrm{IV})$ oxide, or Fe(III) citrate reduction. Some mutants containing only one cluster were able to reduce particular terminal electron acceptors better than the wild type, suggesting routes for improvement by targeting specific electron transfer pathways. Transcriptomic comparisons between fumarate and electrode-based growth conditions showed all of these ext clusters to be constitutive, and transcriptional analysis of the triple-deletion strain containing only ext $A B C D$ detected no significant changes in expression of genes encoding known redox proteins or pilus components. These genetic experiments reveal new outer membrane conduit complexes necessary for growth of G. sulfurreducens, depending on the available extracellular electron acceptor.

IMPORTANCE Gram-negative metal-reducing bacteria utilize electron conduits, chains of redox proteins spanning the outer membrane, to transfer electrons to the extracellular surface. Only one pathway for electron transfer across the outer membrane of Geobacter sulfurreducens has been linked to Fe(III) reduction. However, G. sulfurreducens is able to respire a wide array of extracellular substrates. Here we present the first combinatorial genetic analysis of five different electron conduits via creation of new markerless deletion strains and complementation vectors. Multiple conduit gene clusters appear to have overlapping roles, including two that have never been linked to metal reduction. Another recently described cluster (ExtABCD) was the only electron conduit essential during electrode reduction, a substrate of special importance to biotechnological applications of this organism.

KEYWORDS Geobacter, extracellular electron transfer, multiheme cytochrome, c-type cytochrome conduit, cytochrome electron conduit, multiheme c-type cytochomes
Received 15 June 2018 Accepted 17 July

2018

Accepted manuscript posted online 23 July

2018

Citation Jiménez Otero F, Chan CH, Bond DR 2018. Identification of different putative outer

membrane electron conduits necessary for Fe(III) citrate, Fe(III) oxide, Mn(IV) oxide, or electrode reduction by Geobacter sulfurreducens. J Bacteriol 200:e00347-18. https://doi.org/10.1128/JB.00347-18. Editor Conrad W. Mullineaux, Queen Mary University of London

Copyright $\odot 2018$ Jiménez Otero et al. This is an open-access article distributed under the terms of the Creative Commons Attribution 4.0 International license.

Address correspondence to Daniel R. Bond, dbond@umn.edu. 
icroorganisms capable of extracellular respiration can alter the redox state of particulate metal oxides in soils and sediments, controlling their solubility and bioavailability (1-6). To respire with extracellular metals, bacteria must first transfer electrons from the cell interior to outer surface redox proteins, requiring unique transmembrane pathways compared to those for growth with intracellularly reduced compounds. The use of surface-exposed electron transfer proteins and conductive appendages by these organisms presents opportunities for transformation of heavy metals, biological nanoparticle synthesis, and a new generation of microbially powered electrochemical devices using bacteria grown on electrodes (7-13).

An extracellular electron transfer strategy must overcome several challenges. In Gram-negative cells, a conductive pathway capable of crossing the inner membrane, periplasm, and outer membrane must first be constructed $(14,15)$. Such pathways are capable of delivering electrons to soluble metals or redox-active molecules, but insoluble metal oxides present additional barriers. Fe(III) and $\mathrm{Mn}(\mathrm{IV})$ oxides vary widely in chemistry, surface charge, redox state, and surface area; thus, an additional suite of proteins or appendages such as pili may be needed to link cell surfaces with different terminal minerals (16-18).

Many metal-reducing bacteria can also transfer electrons to electrodes (8, 19-21). Unlike metal oxide particles, electrodes represent unlimited electron acceptors allowing cells in contact with the inorganic surface to support growth of more distant cells, if they can create a conductive network of proteins that relay electrons to cells at the electrode. The physiological and chemical differences between soluble metals, metal particles, and electrodes raise the possibility that different electron transfer proteins are needed to access each kind of extracellular mineral, surface, or molecule.

A model organism widely studied for its ability to reduce a diversity of metals and electrodes is the deltaproteobacterium Geobacter sulfurreducens, and recent work supports a model in which different electron transfer proteins are used depending on substrate conditions. At the inner membrane, where electrons first leave the quinone pool, a combination $c$ - and b-type cytochrome, $\mathrm{CbcL}(22)$, is required only when extracellular metals and electrodes are below redox potentials of $-0.1 \mathrm{~V}$ versus the standard hydrogen electrode (SHE), while the inner membrane c-type cytochrome ImcH (23) becomes essential if acceptors are at higher redox potentials (18). In another example, in the extracellular matrix beyond the cell surface, chemistry rather than redox potential appears to delineate which proteins are essential for electron transfer. The secreted cytochrome OmcZ and pilus-based appendages are primarily linked to electrode growth, while the secreted cytochrome PgcA enhances reduction of Fe(III) oxides without affecting electrode growth (24-31). Between the initial $\mathrm{CbcL} / \mathrm{ImcH}$-dependent event of inner membrane proton motive force generation and extracellular pilus/ OmcZ/PgcA interactions lies the outer membrane, a less understood barrier that was recently found to contain electron transfer proteins of surprising complexity (32-34).

The only known mechanism for nondiffusive electron transfer across the outer membrane is through a transmembrane "electron conduit" consisting of an integral outer membrane protein anchoring a periplasmic multiheme cytochrome to an outer surface lipoprotein cytochrome. By linking redox active cofactors within a membranespanning complex, electron flow is permitted $(32,35)$. The first electron conduit described was the $\sim 210-\mathrm{kDa}$ MtrCAB complex from Shewanella oneidensis, which catalyzes electron transfer across membranes when purified and placed in lipid vesicles (36-38). The $\operatorname{mtr} C A B$ gene cluster is essential for reduction of all tested soluble metals, electron shuttles, metal oxides, and electrodes by S. oneidensis $(37,39,40)$. Related complexes capped with an extracellular dimethyl sulfoxide (DMSO) reductase allow Shewanella to reduce DMSO on the cell exterior, while similar outer membrane conduits support inward electron flow by Fe(II)-oxidizing Rhodopseudomonas TIE-1 cells $(41,42)$.

In G. sulfurreducens, a gene cluster encoding the periplasmic cytochrome OmbB, the outer membrane integral protein $\mathrm{OmaB}$, and lipoprotein cytochrome OmcB forms a conduit complex functionally similar to MtrCAB, though the two complexes lack any sequence similarity (34). This ombB-omaB-omcB gene cluster is duplicated immediately 
downstream in the G. sulfurreducens genome as the nearly identical ombC-omaC-omcC, together forming the $o m c B C$ cluster. Antibiotic cassette insertions replacing omc $B$, as well as insertions replacing the entire ombB-omaB-omcB conduit, decrease growth with $\mathrm{Fe}$ (III) as an electron acceptor, but the impacts differ between reports and growth conditions (43-45). This variability and residual electron transfer activity suggested the presence of alternative pathways able to catalyze electron transfer across the outer membrane (33).

New evidence for undiscovered outer membrane complexes was recently detected in genome-wide transposon data, which showed that insertions in omcB or omcC had no effect on $G$. sulfurreducens growth with electrodes poised at $-0.1 \mathrm{~V}$ versus SHE, a low potential chosen to mimic the redox potential of Fe(III) oxides (46). Transposon insertions within an unstudied four-gene cluster containing c-type cytochrome conduit signatures caused significant defects during growth on the same $-0.1-\mathrm{V}$ electrodes (46). Deletion of this new cluster, named ext $A B C D$, severely affected growth on lowpotential electrodes, while $\triangle \operatorname{ext} A B C D$ mutants still grew similarly to the wild type with $\mathrm{Fe}(\mathrm{III})$ oxides. In contrast, deletion of the entire omcBC cluster had little impact on low-potential electrode growth (46). These data suggested that the outer membrane proteins essential for electron transfer across the membrane might vary depending on environmental conditions. However, these data involved only single deletions without complementation, and whether different gene clusters were necessary across the full range of environmentally relevant conditions, such as higher redox potentials, during growth with mineral forms such as $\mathrm{Mn}(\mathrm{VI})$, or when metals become soluble, was not tested.

Using new markerless deletion methods, we constructed mutants containing all combinations of the four putative conduit clusters on the genome of G. sulfurreducens. Each of these 15 mutants plus 3 strains containing expression vectors were then directly compared with five electron acceptors: Fe(III) and Mn(IV) oxides, poised electrodes at two different redox potentials, and soluble Fe(III) citrate. We found that during metal reduction the largest defects were in $\triangle o m c B C$ strains, but deletion of the newly identified cluster extEFG in the $\triangle o m c B C$ background was necessary to most severely inhibit $\mathrm{Fe}$ (III) reduction, and deletion of all clusters was required to eliminate reduction of both soluble and insoluble metals. Strains containing only a single cluster showed preferences for reduction of different metals, such as the extEFG- and extHIJKL-only strains performing better with $\mathrm{Mn}$ (IV) oxides than Fe(III) oxides. When electrodes were the electron acceptor, only strains lacking ext $A B C D$ showed a growth defect, and this effect was similar at all redox potentials. A strain still containing ext $A B C D$ but lacking all other conduit clusters grew faster and to a higher final density on electrodes, and a complemented strain lacking all other conduit clusters expressing ext $A B C D$ from a vector also grew faster than the wild type. These data provide evidence that different G. sulfurreducens conduit clusters are necessary during extracellular electron transfer depending on the extracellular substrate.

(This article was submitted to an online preprint archive [47].)

\section{RESULTS}

Description of putative outer membrane electron conduit gene clusters. At least five loci can be identified in the G. sulfurreducens genome encoding putative c-type cytochrome electron conduits. This identification is based on three key elements: (i) a multiheme periplasmic c-type cytochrome, (ii) an outer membrane integral protein with transmembrane $\beta$-sheets, and (iii) one or more outer membrane lipoproteins with redox cofactors (Fig. 1A). Two of these regions correspond to the well-studied OmcBbased (ombB-omaB-omcB, GSU2739 to GSU2737) conduit and its nearly identical duplicate OmcC-based operon immediately downstream preceded by a TetR-family repressor partially truncated in its DNA-binding domain (orfS-ombC-omaC-omcC, GSU2733 to GSU2731). For clarity, and due to the fact that omaBC and ombBC are identical, this region is referred to as the $\operatorname{om} B B C$ cluster. The well-characterized duplicate $o m c B C$ cluster was deleted as a single unit (see Materials and Methods for 


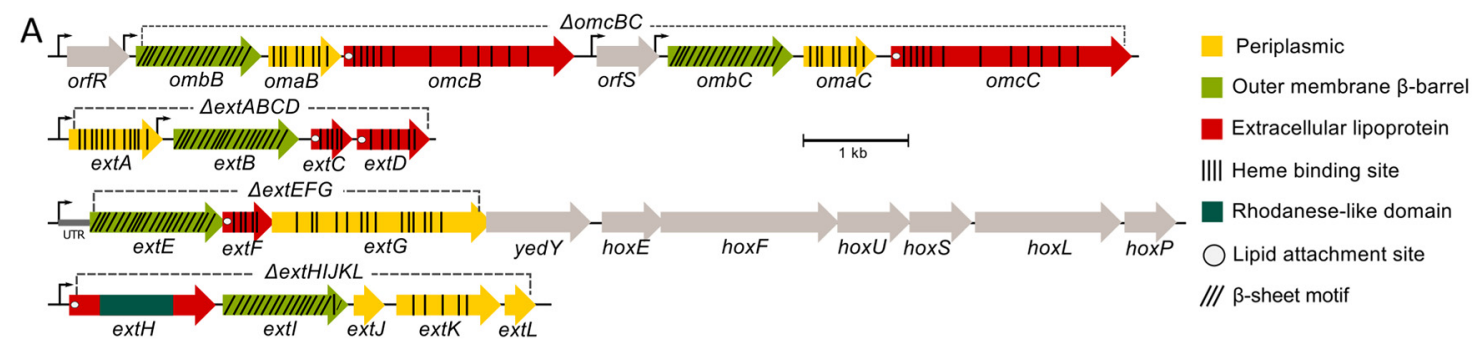

\begin{tabular}{|c|c|c|c|c|c|c|c|c|c|c|c|c|c|c|c|c|c|}
\hline \multicolumn{18}{|c|}{ Percent Identity based on Amino Acid Sequence } \\
\hline \multicolumn{6}{|c|}{ Periplasmic cytochromes } & \multicolumn{6}{|c|}{$\beta$-barrels } & & \multicolumn{5}{|c|}{ Lipoprotein cytochromes } \\
\hline & ExtA & ExtG & ExtK & OmaB & OmaC & & ExtB & ExtE & Extl & OmbB & OmbC & & ExtC & ExtD & ExtF & OmcB & OmcC \\
\hline ExtA & 100 & 25.9 & 17.9 & 23.9 & 23.9 & ExtB & 100 & 30.2 & 21.1 & 22 & 22 & ExtC & 100 & 16.3 & 41.5 & 21.2 & 24.2 \\
\hline ExtG & & 100 & 20.9 & 23.2 & 23.2 & ExtE & & 100 & 20.2 & 20.4 & 20.4 & ExtD & & 100 & 31.3 & 26.9 & 28.5 \\
\hline ExtK & & & 100 & 19.7 & 19.7 & Ext & & & 100 & 17.1 & 17.1 & ExtF & & & 100 & 22.9 & 23 \\
\hline OmaB & & & & 100 & 100 & OmbB & & & & 100 & 100 & OmcB & & & & 100 & 70.8 \\
\hline OmaC & & & & & 100 & OmbC & & & & & 100 & OmcC & & & & & 100 \\
\hline
\end{tabular}

FIG 1 The outer membrane electron conduit gene clusters of G. sulfurreducens. (A) Genetic organization and predicted features of operons containing putative outer membrane conduits. Deletion constructs are indicated by dashed lines. (B) Identity matrix from amino acid sequence alignment of each cytochrome or $\beta$-barrel component using Clustal $\Omega$.

additional information about the tendency of identical genes within this region to recombine during mutant construction and efforts taken to verify proper removal and reconstruction of omcBC genes).

The ext genes comprise three new clusters, named for their putative roles in extracellular electron transfer (46). Relative protein orientations were predicted using a combination of protein localization prediction software (48), integral membrane prediction software (49), and lipid attachment site prediction software (50). The extABCD (GSU2645 to GSU2642) cluster encodes ExtA, a periplasmic dodecaheme c-type cytochrome, ExtB, an outer membrane integral protein with 18 transmembrane domains, and ExtCD, two outer membrane lipoprotein c-type cytochromes with 5 and 12 heme binding sites, respectively. The second cluster, extEFG (GSU2726 to GSU2724), encodes ExtE, an outer membrane integral protein with 21 transmembrane domains, ExtF, an outer membrane lipoprotein pentaheme c-type cytochrome, and ExtG, a periplasmic dodecaheme c-type cytochrome. Kanamycin insertions in ExtG (which in some annotations is referred to as OmcV [51] despite its predicted periplasmic localization) have been shown to affect Fe(III) oxide reduction. For consistency with the surrounding operon and to distinguish it from outer membrane cytochromes, the name ExtG is used in this work. The final cluster, extHIJKL (GSU2940 to GSU2936), lacks an outer membrane c-type cytochrome but encodes ExtH, a rhodanese family lipoprotein, Extl, a 21transmembrane-domain outer membrane integral protein, ExtJ, a small periplasmic protein, and ExtKL, a periplasmic pentaheme c-type cytochrome followed by a small hypothetical protein. A TGA stop codon encoding a predicted rare selenocystine amino acid separates ExtK and ExtL; thus, they may be a single protein (52).

A significant difference between $G$. sulfurreducens Ext clusters and the S. oneidensis Mtr conduits (35) is that the $m t r$ clusters in S. oneidensis are paralogs. The periplasmic MtrA and MtrD cytochromes share over 50\% identity, are similar in size and heme content, and can cross-complement (53). The lipoprotein outer surface cytochromes of Shewanella also demonstrate high sequence, functional, and structural conservation $(32,53-55)$. In contrast, no component of the Ext or OmcB complexes shares any homology. For example, the predicted periplasmic c-type cytochromes ExtA, ExtG, ExtK, and OmaB vary in size from 25 to $72 \mathrm{kDa}$, contain 5 to 15 hemes, and share $18 \%$ to $26 \%$ identity (Fig. 1B).

To screen for physiological roles of these loci, single-cluster mutants were first

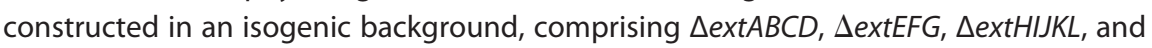
$\triangle$ ombB-omaB-omcB-orfS-ombC-omaC-omcC (abbreviated $\triangle$ omcBC) mutants. Previous studies have reported complementary roles of $\mathrm{OmcB}$ and $\mathrm{OmcC}(43,45)$; thus, the 

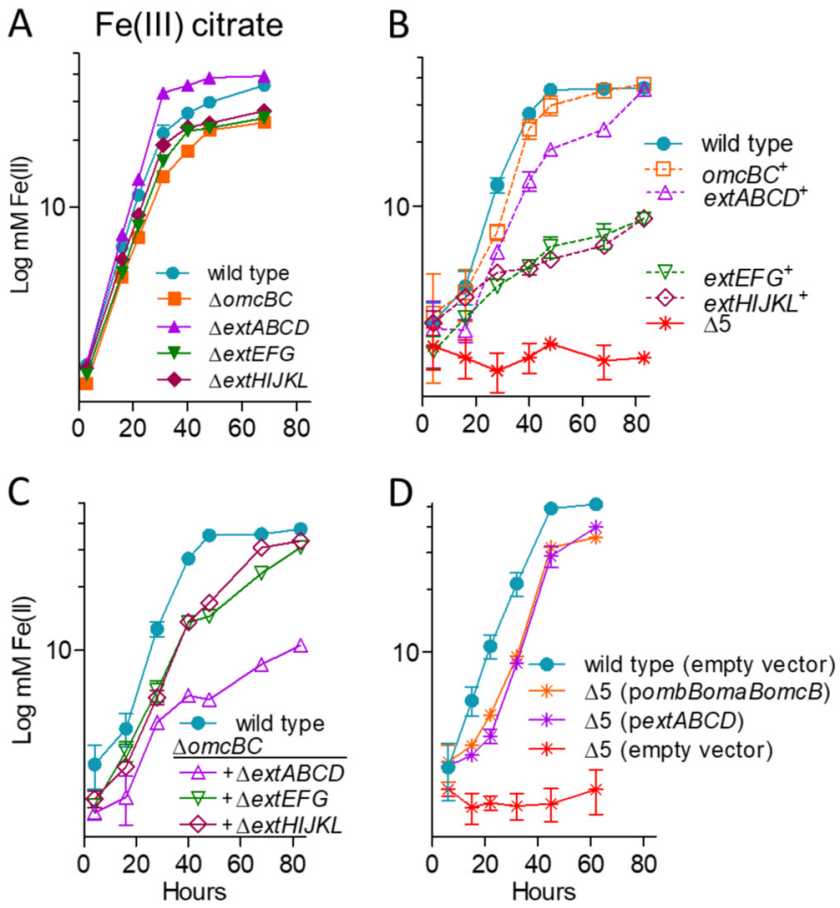

FIG 2 OmcBC or ExtABCD is sufficient during Fe(III) citrate reduction; deletion of all clusters eliminates $\mathrm{Fe}$ (III) citrate reduction. Shown is growth using $55 \mathrm{mM} \mathrm{Fe}$ (III) citrate as an electron acceptor by mutants with single conduit cluster deletions (A), triple mutants lacking all but one cytochrome conduit, as well as the $\Delta 5$ strain lacking all five cytochrome conduits (B), mutants in an $\triangle o m c B C$ background (C), and $\triangle 5$ mutants expressing $o m C B$ or ext $A B C D$ or carrying an empty expression vector as control (D). All experiments were conducted in triplicate, and curves are averages \pm standard deviations (SDs) from $\geq 3$ replicates.

entire $o m c B C$ cluster was removed to screen for conditions under which this pair of homologous conduits were necessary. As these single mutant strains lacked any antibiotic cassettes, they could be used as backgrounds for further double and triple deletions. Multiple-cluster-deletion mutants leaving only one conduit cluster on the genome are referred to by their remaining cluster; e.g., the extABCD+ mutant contains only ext $A B C D$ and is equivalent to the $\triangle$ extEFG $\triangle$ extHIJKL $\triangle O M C B C$ mutant, while the mutant lacking all extABCD, extEFG, extHIJKL, omcB-based, and omcC-based clusters is referred to as " $\triangle 5$." After whole-genome resequencing of all terminal strains containing single clusters and the strain missing all clusters (such as the extABCD+ and $\triangle 5$ mutants) to verify that no off-target mutations accumulated during the many rounds of insertion and recombination, all of these strains were tested under six different extracellular growth conditions varying in solubility, chemical composition, and redox potential.

Cells lacking single gene clusters have only partial reduction defects with $\mathrm{Fe}(\mathrm{III})$ citrate. Soluble Fe(III) citrate was the simplest extracellular electron acceptor tested in this study, requiring no attachment to a surface and requiring no appendages, such as pili, or secreted cytochromes for reduction. Under these conditions, no singlecluster deletion eliminated the majority of soluble $\mathrm{Fe}$ (III) citrate reduction. The most severe defect was observed in the $\triangle o m c B C$ cluster mutant, which grew slower than any other single mutant and reduced only $60 \%$ of the Fe(III) citrate reduced by the wild type (Fig. 2A). Minor defects were also observed for the $\triangle$ extEFG and $\triangle$ extHIJKL mutants, while the $\triangle \operatorname{ext} A B C D$ mutant reduced Fe(III) citrate at wild-type levels. These results suggested that more than one cluster was necessary for wild-type soluble $\mathrm{Fe}$ (III) reduction.

Any one gene cluster is sufficient for partial Fe(III) citrate reduction, and deletion of all $\mathbf{5}$ clusters eliminates electron transfer to this substrate. Deletion of the full suite of clusters was the only combination that eliminated all residual electron 
transfer to $\mathrm{Fe}(\mathrm{III})$ citrate (Fig. 2B). When multiple-deletion strains still containing one cluster were tested for $\mathrm{Fe}(\mathrm{III})$ citrate reduction, results supported key roles for omcBC and ext $A B C D$ in soluble metal reduction and little involvement by extEFG or extHIJKL. For example, $\mathrm{Fe}(\mathrm{III})$ citrate reduction by the $\mathrm{omCBC} C^{+}$and extABCD+ mutants was comparable to that by the wild type, while extEFG ${ }^{+}$and extHIJKL ${ }^{+}$strains reduced Fe(III) citrate to just $20 \%$ of the value for the wild type.

Only strains lacking both omCBC and ext $A B C D$ had a significant defect in Fe(III) citrate reduction. Because $\triangle O m C B C$ demonstrated the largest defect in Fe(III) citrate reduction, additional deletions in this background were tested for the ability to reduce this substrate (Fig. 2C). Only the double-cluster-deletion $\triangle$ omcBC $\triangle$ ext $A B C D$ mutant reduced $\mathrm{Fe}(\mathrm{III})$ citrate at a significantly lower rate than the $\triangle o m C B C$ strain, which agreed with the robust growth seen in strains containing only $o m C B C^{+}$or ext $A B C D^{+}$. The $\triangle o m c B C \triangle \operatorname{ext} A B C D$ mutant (still containing both extEFG and extHIJKL) reduced Fe(III) citrate poorly, to the same level as their single-cluster strains containing only extEFG ${ }^{+}$ or extHIJKL+ (Fig. 1B versus Fig. 2C). These data suggested that when both extEFG and extHIJKL remained in the genome, their contribution was not additive.

Not shown in Fig. 2 are metal reduction data for intermediate deletion mutants with no additional phenotype, such as the $\triangle$ extEFG $\triangle$ extHIJKL mutant. Experiments performed after such double mutants were constructed revealed no changes that deviated from the wild type or their parent single-cluster deletions. Only intermediate strains with additive phenotypes, such as strains in the $\triangle o m c B C$ background, are shown in Fig. 2.

Expression of single conduit clusters from vectors is sufficient to recover Fe(III) citrate reduction. Compared to empty-vector controls, complementation of the $\Delta 5$ strain with single om $B$ (as ombB-omaB-omcB) or ext $A B C D$ clusters restored Fe(III) citrate reduction to levels within $90 \%$ of those of the respective omcBC $C^{+}$and ext $A B C D^{+}$strains (Fig. 2D). Previous studies have also shown that expression of only the omcB-based cluster is sufficient to rescue ferric citrate reduction defects in a $\triangle o m c B C$ strain (45), but ext $A B C D$ has never been used to rescue a respiratory phenotype. These data are the first evidence that a putative outer membrane complex other than those encoded in omc $B$ could be sufficient for extracellular metal reduction in Geobacter.

Only strains lacking multiple gene clusters have significant defects in Fe(III) and $\mathbf{M n}$ (IV) oxide reduction. Particulate metal oxides represent substrates of additional complexity, requiring pili and additional cytochromes for long-range electron transfer to particles or surfaces after transmembrane electron transfer. Because they are not hypothesized to act as the interface with distant electron acceptors, it was possible that the outer membrane complex mutants would show less specificity during reduction of $\mathrm{Fe}(\mathrm{III})$ or $\mathrm{Mn}(\mathrm{IV})$ oxides. However, trends remained similar to those for Fe(III) citrate, where deletion of single conduit clusters in G. sulfurreducens had only modest effects on metal oxide reduction (Fig. $3 \mathrm{~A}$ and $\mathrm{C}$ ) and additional conduit cluster deletions were needed to severely impact growth (Fig. 3B and D). The most severe defect was again observed in the $\triangle O M C B C$ cluster mutant, which reduced $68 \%$ of $\mathrm{Fe}$ (III) oxide compared to the wild type (Fig. 3A). Minor defects were observed for single $\triangle$ extEFG and $\triangle$ extHIJKL deletions, while $\triangle$ extABCD reduced Fe(III) oxide near wild-type levels. In contrast, none of the single mutants displayed defects with $\mathrm{Mn}$ (IV) oxides (Fig. $3 \mathrm{C}$ ).

Unlike soluble metal reduction, however, results supported roles for omcBC and extEFG in metal oxide reduction and little involvement by ext $A B C D$. For example, in strains containing only one cluster, $\mathrm{Fe}(\mathrm{III})$ oxide reduction by the omcBC$C^{+}$mutant was nearly $80 \%$ that of the wild type, reduction by the extEFG ${ }^{+}$mutant was over $60 \%$, but the ext $A B C D^{+}$strain reduced less than $30 \%$ that by the wild type. Similarly, the omcBC ${ }^{+}$, extEFG ${ }^{+}$, and extHIJKL ${ }^{+}$strains achieved about $80 \%$ of wild-type $\mathrm{Mn}$ (IV) oxide reduction at $80 \mathrm{~h}$, but the extABCD+ strain again displayed poor $\mathrm{Mn}(\mathrm{IV})$ oxide reduction. As with soluble metal reduction, deletion of the full suite of clusters was necessary to eliminate all residual electron transfer to either Fe(III) or Mn(IV) oxides (Fig. 3B and D).

Only strains lacking both omcBC and extEFG had a significant defect in Fe(III) and $M n(I V)$ oxide reduction. Since the $\triangle O M C B C$ mutant demonstrated the largest defect in Fe(III) oxide reduction, additional deletions in this background were tested 

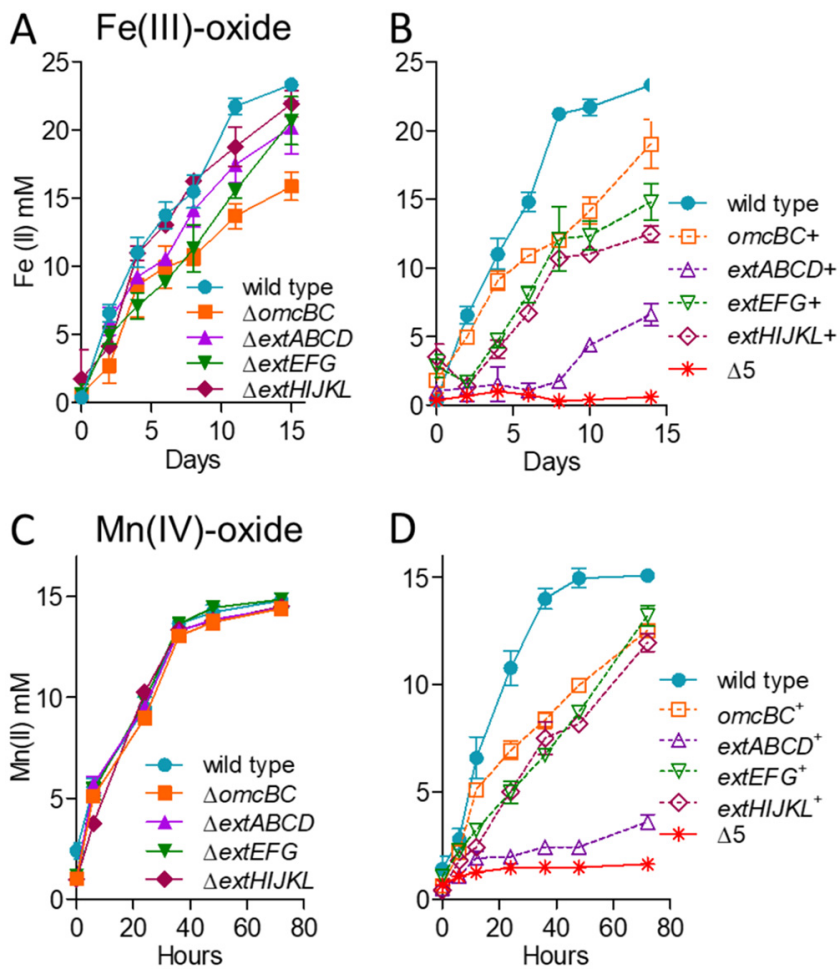

FIG 3 No single outer membrane cluster is essential but all are necessary for wild-type levels of electron transfer to $\mathrm{Fe}(\mathrm{III})$ and $\mathrm{Mn}(\mathrm{IV})$ oxides. Shown is growth of single-cluster-deletion mutants and triple mutants lacking all but one cytochrome conduit cluster, as well as the $\Delta 5$ mutant lacking all clusters utilizing $70 \mathrm{mM} \mathrm{Fe}$ (III) oxide (A and B) or $20 \mathrm{mM} \mathrm{Mn(IV)}$ oxide (C and D) as the terminal electron acceptor. All experiments were conducted in triplicate, and curves are averages \pm SD from $\geq 3$ replicates.

during $\mathrm{Fe}(\mathrm{III})$ and $\mathrm{Mn}$ (IV) oxide reduction (Fig. 4). Fe(III) oxide reduction by the $\triangle \mathrm{omc} B C$ $\triangle$ extEFG mutant was less than $25 \%$ that of the wild type, while the $\triangle$ omcBC $\triangle \operatorname{ext} A B C D$ and $\triangle o m c B C \triangle$ extHIJKL strains still reduced Fe(III) oxides similarly to the $\triangle o m c B C$ strain. The additive effect from the $\triangle$ extEFG mutant agreed with data from mutants containing single clusters, where the $\mathrm{omCBC}^{+}$and extEFG ${ }^{+}$mutants showed the best reduction. The $\triangle o m c B C \triangle \operatorname{extEFG}$ strain also had a severe $\mathrm{Mn}(\mathrm{IV})$ oxide reduction defect. However, unlike Fe(III) oxide reduction, the $\triangle \mathrm{omcBC} \triangle \operatorname{ext} A B C D$ and $\triangle \mathrm{omcBC} \triangle \mathrm{extHIJKL}$ double deletion strains had only a modest $\mathrm{Mn}(\mathrm{IV})$ oxide reduction defect, suggesting higher
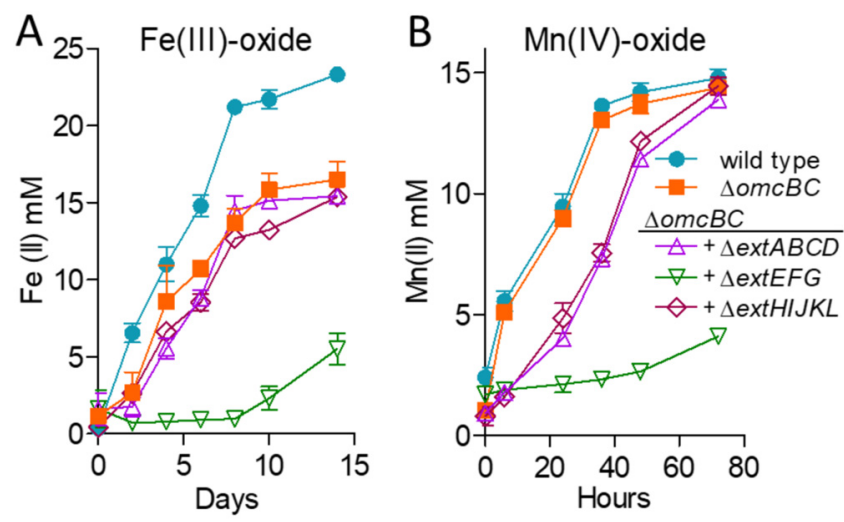

FIG $4 \mathrm{OmcBC}$ and ExtEFG have additive roles in Fe(III) and $\mathrm{Mn}(\mathrm{IV})$ oxide reduction. Shown is reduction of $70 \mathrm{mM} \mathrm{Fe}(\mathrm{III})$ oxide (A) or $20 \mathrm{mM} \mathrm{Mn}(\mathrm{IV})$ oxide (B) by the $\triangle$ omcBC strain and additional deletions in an $\triangle o m c B C$ background. All experiments were conducted in triplicate, and curves are averages \pm SD from $\geq 3$ replicates. 

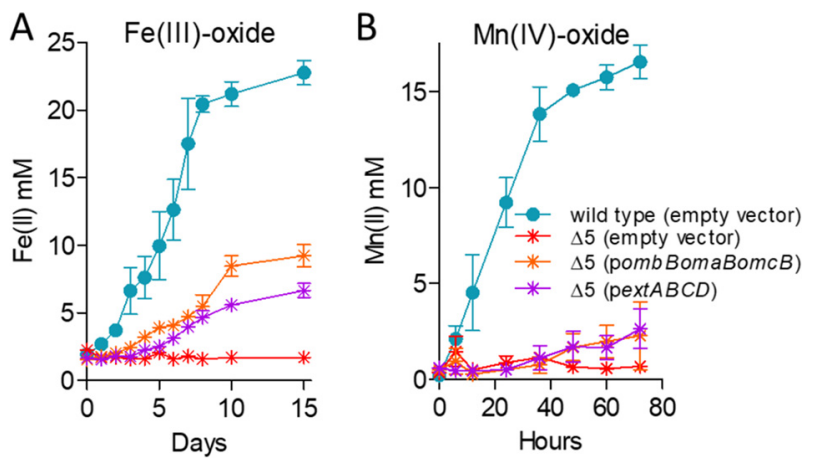

FIG 5 Partial complementation by single conduit clusters supports the hypothesis that multiple conduit complexes are necessary for wild-type levels of metal oxide reduction. Shown is reduction of $70 \mathrm{mM}$ Fe(III) oxide (A) or $20 \mathrm{mM} \mathrm{Mn(IV)} \mathrm{oxide} \mathrm{(B)} \mathrm{by} \mathrm{the} \triangle 5$ mutant expressing extABCD or the omcB cluster compared to the empty vector control. All experiments were conducted in triplicate, and curves are averages $\pm \mathrm{SD}$ from $\geq 3$ replicates.

contributions of the extABCD and extHIJKL clusters during Mn(IV) than during Fe(III) oxide reduction.

The poor growth of the $\triangle O m c B C \triangle \operatorname{extEFG}$ mutant with insoluble metals was surprising, since this strain still contained extHIJKL. When extHIJKL was the only cluster remaining, the extHIJKL ${ }^{+}$strain reduced up to $50 \%$ of the $\mathrm{Fe}(\mathrm{III})$ oxide and $75 \%$ of the $\mathrm{Mn}(\mathrm{IV}$ ) oxide reduced by the wild type (Fig. 3B and D). This was a rare case in which a mutant containing the single cluster performed better than predicted by single and double mutants and raises the hypothesis that extHIJKL expression or function is partially inhibited by the presence of extABCD. No other ext or omc cluster showed this kind of behavior with soluble or insoluble metals.

Expression of single conduit clusters partially recovers $\mathrm{Fe}$ (III) and $\mathrm{Mn}$ (IV) oxide reduction. Plasmids containing constitutive $o m b B$-omaB-omc $B$ or ext $A B C D$ clusters resulted in partial recovery (Fig. 5), consistent with the intermediate phenotypes displayed by mutants retaining these single clusters on the genome. Expression of the omcB cluster reestablished Fe(III) oxide reduction to a level less than that seen in the omcBC ${ }^{+}$strain containing the full duplicated cluster in its original context, suggesting that both omcB and omcC are necessary (Fig. 4B). Expressing extABCD from a plasmid restored $\mathrm{Fe}(\mathrm{III})$ oxide reduction in the $\triangle 5$ strain near the low levels of the extABCD+ strain, and reduction of $\mathrm{Mn}(\mathrm{IV})$ oxides by $o m C B$ - or ext $A B C D$-expressing strains was even lower. These data again agreed with the partial reduction phenotype of mutant strains containing only extABCD.

Mutants lacking ext $A B C D$ are defective in electrode growth at all redox potentials, while mutants containing only ext $A B C D$ outperform the wild type. In contrast to metal reduction, when strains were grown as biofilms on electrodes poised at high $(0.24 \mathrm{~V}$ versus $\mathrm{SHE})$ or low $(-0.1 \mathrm{~V}[46])$ redox potentials, only $\triangle$ ext $A B C D$ mutants showed a defect in both the rate and extent of growth. Mutants lacking the omCBC and extEFG clusters grew at rates similar to that of the wild type, while the $\triangle$ extHIJKL mutant demonstrated a lag before growing with a doubling time similar to that of the wild type (Fig. 6A). In all experiments, the $\triangle$ ext $A B C D$ mutant grew poorly, without a clear exponential phase. The apparent doubling time of the $\triangle$ ext $A B C D$ mutant was longer than $20 \mathrm{~h}$, or over 3 -fold slower than that of the wild type, and reached only $20 \%$ of wild-type final current density, or $116 \pm 33 \mu \mathrm{A} / \mathrm{cm}^{2}$ versus $557 \pm 44 \mu \mathrm{A} / \mathrm{cm}^{2}$ ( $n \geq 5$ per strain).

Mutants containing only one gene cluster (extABCD${ }^{+}$, extEFG ${ }^{+}$, extHIJKL ${ }^{+}$, and omcBC ${ }^{+}$mutants) as well as a mutant lacking all gene clusters $(\triangle 5)$ were then analyzed for growth on electrodes. The $\triangle 5$ mutant grew at the same low, nonexponential rate as the $\triangle \operatorname{ext} A B C D$ single mutant at both redox potentials, suggesting that none of the additional clusters were responsible for residual growth rate originally seen in the $\triangle$ ext $A B C D$ mutant. In contrast, the ext $A B C D^{+}$mutant grew faster than the wild type (doubling time, $4.5 \pm 0.2 \mathrm{~h}$ versus $6.5 \pm 0.3 \mathrm{~h} ; n \geq 9$ ) and reached a final current density 

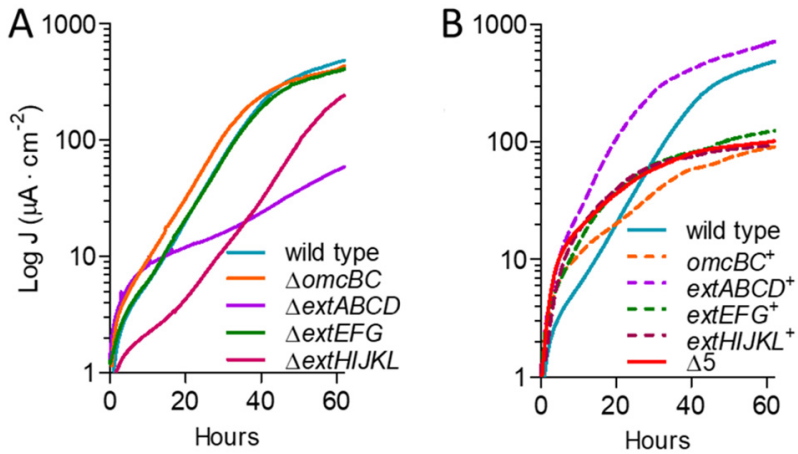

FIG 6 Only the ExtABCD conduit cluster is necessary for electrode reduction. Shown is current density produced by single- (A) and multiple (B)-cluster-deletion mutants on graphite electrodes poised at +0.24 $\mathrm{V}$ versus SHE. All mutants were grown in at least two separate experiments, and curves are representative of results from $\geq 3$ independent replicates per experiment. Similar results were obtained at lower $(-0.1$ $\mathrm{V}$ versus $\mathrm{SHE}$ ) redox potentials.

$40 \%$ higher than that of the wild type $\left(768 \pm 52 \mu \mathrm{A} / \mathrm{cm}^{2}\right.$ versus $557 \pm 44 \mu \mathrm{A} / \mathrm{cm}^{2} ; n \geq$ 9 ). All other multiple-deletion strains containing only one cluster grew as poorly as the $\triangle 5$ mutant, further indicating that under these conditions, extEFG, extHIJKL, and omcBC were not necessary or sufficient to restore electron transfer to electrodes (Fig. 6B). We were unable to identify the origin of the slow growth enabling residual electron transfer to electrodes, although $G$. sulfurreducens contains at least 3 other multiheme cytochrome-rich regions with conduit-like signatures that remain to be examined.

A 5-conduit deletion mutant expressing ext $A B C D$ has a higher growth rate on electrodes than the wild type. To further investigate the specific effect of ext $A B C D$ on electrode growth, ext $A B C D$ was provided on a vector in the $\triangle 5$ strain. The 3-gene omcB conduit cluster (ombB-omaB-omcB) was also placed in the $\Delta 5$ strain using the same vector, and both were compared to wild-type cells containing the empty vector. While the plasmid is stable for multiple generations, routine vector maintenance requires growth with kanamycin, and kanamycin carryover into biofilm electrode experiments is reported to have deleterious effects on electrode growth $(23,56)$. Thus, we first reexamined growth of the empty-vector strain. When selective levels of kanamycin (200 $\mu \mathrm{g} \cdot \mathrm{ml}^{-1}$ ) were present in electrode reactors, colonization slowed and final current production decreased $74 \%$ even though cells carried a kanamycin resistance cassette. At levels resulting from carryover during passage of cells into the electrode reactor (5 $\mu \mathrm{g} \cdot \mathrm{ml}^{-1}$ ) the growth rate of vector-containing cells was not affected but final current was decreased up to $30 \%$, suggesting interference with biofilm formation rather than respiration (Fig. 7A). All subsequent complementation was performed in the presence of $5 \mu \mathrm{g} \cdot \mathrm{ml}^{-1}$ of residual kanamycin and compared to these controls.

Expressing the $o m c B$ conduit cluster in the $\Delta 5$ strain failed to increase growth with electrodes as electron acceptors. These data were consistent with the lack of an effect seen in $\triangle o m c B C$ deletions and with the poor growth of $o m c B C^{+}$mutants that still contained both the $\mathrm{OmcB}$ and $\mathrm{OmcC}$ clusters in their native genomic context (Fig. 7B). In contrast, when extABCD was expressed on the same vector in the $\triangle 5$ background, colonization was faster and cells reached a higher final current density than for the wild type carrying the empty vector (421 $\pm 89 \mu \mathrm{A} / \mathrm{cm}^{2}$ versus $297 \pm 11 \mu \mathrm{A} / \mathrm{cm}^{2} ; n=3$ ) (Fig. $7 B)$. This enhancement by plasmid-expressed extABCD (141\% of that of the wild type with empty vector) was similar to the positive effect observed in the extABCD+ strain (137\% of that of the wild type) (Fig. 6B) and further supported the hypothesis that ext $A B C D$ is both necessary and sufficient during growth with electrodes.

Growth of any two-conduit deletion mutant was unchanged from single-cluster strains (see Fig. $\mathrm{S} 1$ in the supplemental material). For example, just as the mutant lacking ext $A B C D$ produced the same phenotype as the $\triangle 5$ strain (Fig. 6), deletion of a second cluster from the $\triangle \operatorname{ext} A B C D$ strain produced results similar to those for the 

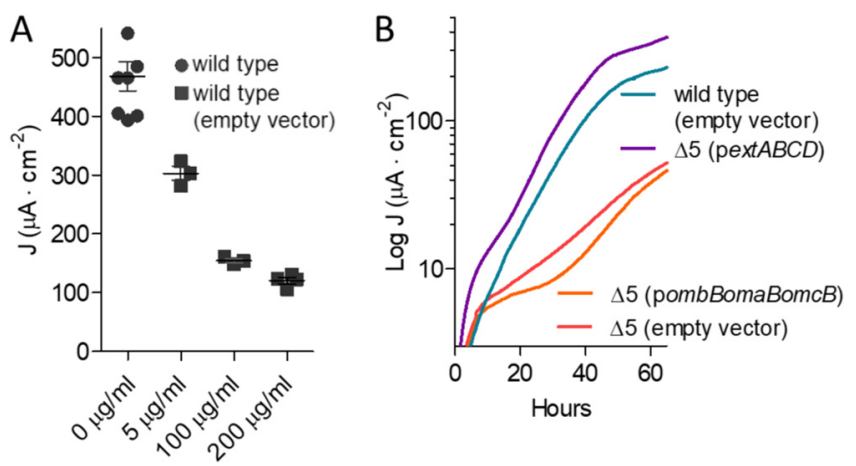

FIG 7 Effect of kanamycin on final current density and comparison of ExtABCD and OmcBC complementation. (A) Final current density of wild-type G. sulfurreducens compared to the wild type carrying an empty vector in the presence of increasing kanamycin concentrations. (B) Current density produced by the $\triangle 5$ strain plus either extABCD or omCB cluster-containing vectors in the presence of $5 \mu \mathrm{g} / \mathrm{ml}$ residual kanamycin. Wild-type and $\Delta 5$ strains carrying the empty vector were used as controls. All experiments were conducted in duplicate, and curves are representative of results from $\geq 3$ replicates per experiment.

$\triangle \operatorname{ext} A B C D$ mutant, and no two-cluster combination of omcBC, extEFG, or extHIJKL showed defects to suggest that they were required under electrode growth conditions or to indicate that their presence affected expression of extABCD. The $\triangle \operatorname{ext} A B C D$ and $\triangle 5$ strains were also monitored during extended incubation times to determine if final current density increased after a prolonged incubation period, but the current remained unchanged even after $200 \mathrm{~h}$ (Fig. S2).

Transcriptomic analysis reveals no differential expression of putative conduit clusters during growth on electrodes or off-target expression effects in extABCD+. The importance of the ext $A B C D$ gene cluster during electrode growth was first discovered via genetic experiments (46), but none of the ext genes described here have been highlighted or examined in earlier studies measuring transcriptional or proteomic changes. Since data are available only from microarray studies comparing stationaryphase electrode biofilms with $>4$-day-old fumarate biofilms grown under electron donor limitation (24), or comparing stationary-phase electrode biofilms with Fe(III) citrate-grown cells (57), few conclusions could be drawn from previous studies. As mature biofilms contain many layers of inactive or slowly growing cells (58), we conducted new experiments capturing both fumarate- and electrode-grown cells during exponential growth to determine absolute levels of transcriptional abundance for ext and omc genes, using transcriptome sequencing (RNA-seq).

Figure 8A compares expression levels of wild-type G. sulfurreducens during exponential fumarate growth and exponential growth with electrodes, using data averaged from at least 2 biological replicates under each condition. Despite the fact that this represents a shift from planktonic cells using an intracellularly reduced acceptor to biofilms using an extracellular acceptor, few genes undergo changes of $>2 \log _{2}$. Highlighted in Fig. 8A are all annotated cytochromes and pilus genes reported to be involved in metal or electrode respiration, showing that nearly all of these were constitutively expressed between the two laboratory conditions of nonlimiting electron acceptor.

Compared to the highly expressed omcBC genes, genes for ext $A B C D$ and other ext clusters were expressed at levels equivalent to only 10 to $20 \%$ of omcB under both conditions, which may explain OmcB's dominance in prior gel-based heme stain identification and proteomic analyses. We did observe an overall trend of increased cytochrome and electron transfer gene expression during growth on electrodes, reflecting a general increase in extracellular respiratory processes, but these changes occurred in both essential and nonessential genes. Genes encoding the characterized inner membrane electron transfer proteins $\mathrm{ImcH}$ and $\mathrm{CbcL}$ also did not change significantly in expression between these two conditions, nor did any genes for periplasmic cytochromes or pilus components known to be essential $(18,22,23)$. As has been 


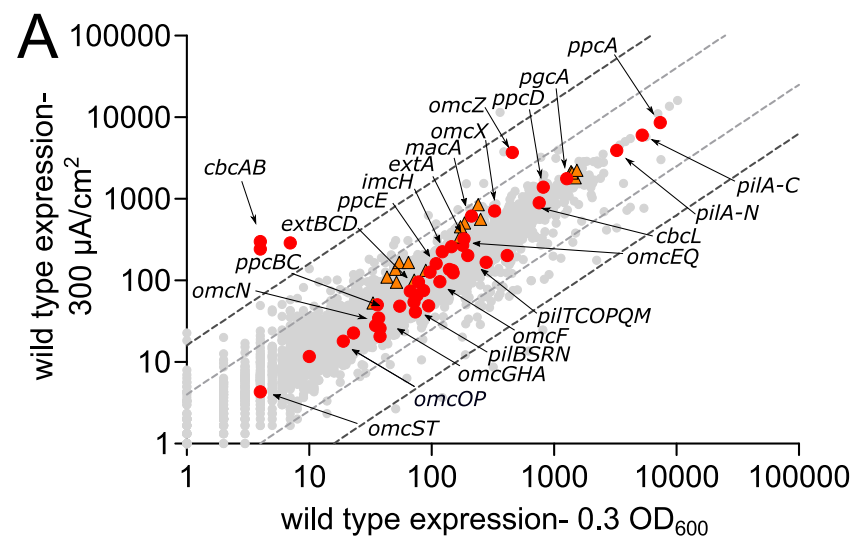

\begin{tabular}{|c|c|c|c|c|c|}
\hline \multirow{2}{*}{$\begin{array}{l}\text { gene } \\
\text { symbol }\end{array}$} & \multirow{2}{*}{ locus } & \multirow{2}{*}{ annotation } & \multicolumn{2}{|c|}{ RPKM } & \multirow{2}{*}{ Log $_{2}$ change } \\
\hline & & & fumarate & electrode & \\
\hline$c b c A$ & GSU0593 & cytochrome b & 4 & 301 & 6.23 \\
\hline$c b c B$ & GSU0594 & cytochrome c & 4 & 242 & 5.92 \\
\hline omcZ & GSU2076 & cytochrome c & 456 & 3717 & 3.03 \\
\hline $\operatorname{extD}$ & GSU2642 & lipoprotein cytochrome c & 36 & 50 & 0.48 \\
\hline extc & GSU2643 & lipoprotein cytochrome c & 78 & 95 & 0.29 \\
\hline extB & GSU2644 & OM integral protein & 97 & 126 & 0.38 \\
\hline extA & GSU2645 & cytochrome c & 184 & 323 & 0.81 \\
\hline extG & GSU2724 & cytochrome c & 47 & 104 & 1.15 \\
\hline extF & GSU2725 & lipoprotein cytochrome c & 56 & 91 & 0.70 \\
\hline extE & GSU2726 & OM integral protein & 55 & 131 & 1.25 \\
\hline omcC & GSU2731 & lipoprotein cytochrome c & 261 & 803 & 1.62 \\
\hline omac & GSU2732 & cytochrome c & 1455 & 1917 & 0.40 \\
\hline$a m b C$ & GSU2733 & OM integral protein & 1492 & 2038 & 0.45 \\
\hline$o m c B$ & GSU2737 & lipoprotein cytochrome c & 1614 & 1717 & 0.09 \\
\hline$o m a B$ & GSU2738 & cytochrome c & 1524 & 1971 & 0.37 \\
\hline$a m b B$ & GSU2739 & OM integral protein & 1667 & 2127 & 0.35 \\
\hline extL & GSU2936 & hypothetical protein & 59 & 157 & 1.42 \\
\hline extk & GSU2937 & cytochrome c & 70 & 158 & 1.18 \\
\hline ext & GSU2938 & hypothetical protein & 272 & 534 & 0.97 \\
\hline extI & GSU2939 & OM integral protein & 201 & 480 & 1.26 \\
\hline extH & GSU2940 & Iron-sulfur protein & 187 & 434 & 1.21 \\
\hline
\end{tabular}
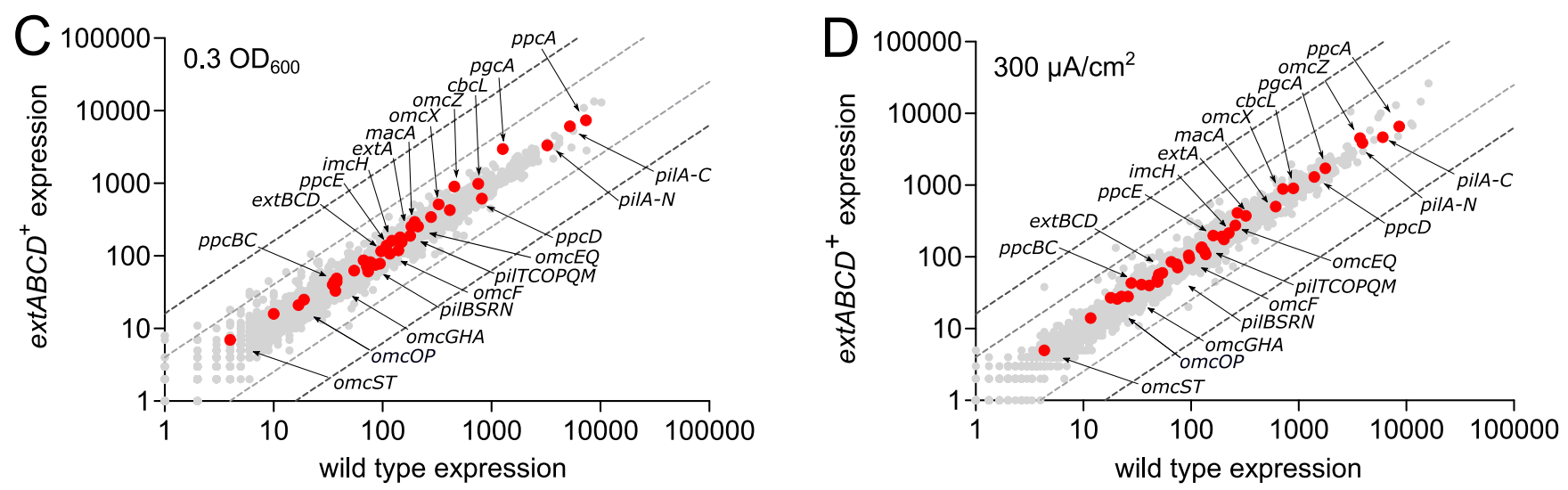

FIG 8 Transcriptomic analysis comparing fumarate versus electrode growth for ext $A B C D^{+}$and wild-type strains. (A) Comparison of expression levels of wild-type exponentially growing cells under fumarate- and electrode-respiring conditions, showing no significant up- or downregulation of ext clusters (orange triangles) or most other known electron transfer proteins (red circles). Dark and light gray dotted lines represent thresholds of 4 and 2 log 2 , respectively. (B) RPKM and $\log _{2}$ change of open reading frames with largest expression changes as well as genes studied in this work (for additional data, see Table S2). (C and D) Comparison of the transcriptomes of wild-type and ext $A B C D^{+}$cells exponentially growing using fumarate (C) or electrode poised at $+240 \mathrm{mV}(\mathrm{D})$ as the terminal electron acceptor, showing no changes to electron transfer proteins due to deletion of omBC, extEFG, and extHIJKL clusters. Averages of biological replicate samples are shown.

shown before (24), the well-characterized extracellular cytochrome omcZ was upregulated over 8-fold during electrode reduction, and a putative inner membrane $c$ - and $b$-type cytochrome similar to $\mathrm{CbcL}$ that is upregulated during $\mathrm{Fe}(\mathrm{III})$ reduction $(c b c B A)$ also increased over 30-fold (51) (Fig. 8A). A table providing data for reads per kilobase per million (RPKM) for all genes studied in this investigation, along with omc $Z$ and $c b c B A$, is provided in Fig. $8 \mathrm{~B}$. As none of the extABCDEFGHIJKL genes were strongly induced or repressed during electrode growth and these genes were generally expressed at levels $1 / 10$ of the omcBC locus, their absence from prior differential expression analyses is understandable. Under these conditions, G. sulfurreducens appears to maintain low constitutive levels of most inner and outer membrane electron transfer proteins regardless of the substrate. While low expression is common for membrane proteins, constitutive expression even when the gene is not strictly necessary differs from well-studied substrate-dependent transcriptional profiles of model heterotrophs. One hypothesis is that the diverse nature of extracellular substrates encountered by $G$. sulfurreducens in nature resembles more the variety of polysaccharides encountered by cellulolytic bacteria in the environment, which causes them to maintain constitutive expression of $\beta$-glucosidases independent of the presence of the substrate (59).

A second question that often arises in the study of complex phenotypes is whether deletion of an important or highly expressed cluster, such as omcBC, affects expression of other genes, especially as phenotypes such as biofilm growth require secretion of complexes to the outer membrane, adhesion of cells to surfaces, and production of 
TABLE 1 Comparative performance of G. sulfurreducens strains lacking one cluster or containing only one cluster ${ }^{a}$

\begin{tabular}{|c|c|c|c|c|c|c|c|c|c|}
\hline \multirow[b]{2}{*}{ Substrate } & \multicolumn{9}{|c|}{$\%$ of wild type growth } \\
\hline & $\triangle o m c B C$ & $\triangle \operatorname{ext} A B C D$ & $\Delta$ extEFG & $\Delta$ extHIJKL & omcBC $C^{+}$ & $\operatorname{ext} A B C D^{+}$ & extEFG ${ }^{+}$ & extHIJKL+ & $\Delta 5$ \\
\hline$\overline{\mathrm{Fe}(\mathrm{III}) \text { citrate }}$ & $61.2 \pm 10.5$ & $105 \pm 6.6$ & $62.5 \pm 4.9$ & $66.3 \pm 2.5$ & $101.1 \pm 8.4$ & $99.2 \pm 11.3$ & $22.5 \pm 2.4$ & $23.8 \pm 6.4$ & $0.1 \pm 0.6$ \\
\hline FellI) oxide & $68.9 \pm 8.4$ & $83.3 \pm 12.1$ & $87.5 \pm 14.9$ & $95.8 \pm 24.9$ & $78.8 \pm 3.9$ & $29.2 \pm 2.6$ & $60.4 \pm 9.5$ & $52.1 \pm 3.7$ & $0.1 \pm 0.3$ \\
\hline Electrode & $76.5 \pm 16.5$ & $20.9 \pm 6.0$ & $104.8 \pm 2.1$ & $86.3 \pm 15.3$ & $28.3 \pm 5.2$ & $137.9 \pm 9.5$ & $21.2 \pm 6.5$ & $25.9 \pm 4.2$ & $21.9 \pm 4.4$ \\
\hline
\end{tabular}

${ }^{a}$ Growth of single cytochrome conduit deletion mutants and mutants lacking all clusters except one, averaged from eight biological replicates or more and represented as percentage of wild-type growth. Averages and standard deviations are represented.

extracellular proteins such as pili (60-62). The fact that the ext $A B C D^{+}$strain lacking 15 different genes always grew faster than the wild type, and produced more current than the wild type, raised a significant question regarding possible off-target effects on other aspects of metabolism. Therefore, the transcriptome of the extABCD+ strain was analyzed under both fumarate- and electrode-respiring conditions and compared to that of the wild type.

No significant increase or decrease in expression of any previously studied electron transfer proteins were found during growth in fumarate, or during exponential growth on electrodes, when the extABCD+ strain was compared to the wild type (Fig. $8 \mathrm{C}$ and $D)$. This further suggested that the increased growth rate was not due to altered expression of an unknown gene affecting electron transfer or attachment. It also underscored the trend in Geobacter that many genes, such as omcB, are among the most highly expressed under laboratory conditions, yet these expression levels have not correlated with essentiality or function on electrodes. The full data sets plotted in Fig. 8 can be found in Table S2.

Summary of phenotypes for all Omc and Ext electron conduit gene cluster mutants. Table 1 summarizes all extracellular reduction phenotypes of single-cluster deletions and deletions leaving only one conduit on the genome, adjusted to wild-type performance. Each gene cluster was necessary under different conditions. Many of the recently described ext gene clusters were necessary for wild-type metal reduction, yet few were sufficient. For example, extEFG and extHIJKL were necessary for Fe(III) citrate reduction, as strains lacking these clusters reduced only $\sim 65 \%$ of wild-type levels. But when only extEFG or only extHIJKL was present, they were not sufficient to reduce $\mathrm{Fe}(\mathrm{III})$ citrate at wild-type levels. In contrast, the ${ }^{\prime} m B C$ cluster or the ext $A B C D$ cluster alone was necessary for $\mathrm{Fe}(\mathrm{III})$ citrate reduction, and the ext $A B C D$ cluster alone was also sufficient for electrode growth. Deletion of all five conduit clusters resulted in complete elimination of metal reduction abilities, while some residual activity remained when the same $\Delta 5$ strain was grown using electrodes as terminal electron acceptors. These comparisons show that each gene cluster is necessary under at least one of the conditions studied and provide evidence for additional undiscovered mechanisms enabling transmembrane electron transfer during electrode growth.

\section{DISCUSSION}

Sequencing of the G. sulfurreducens genome revealed an unprecedented number of electron transfer proteins, with twice as many genes dedicated to respiratory and redox reactions as in organisms with similarly sized genomes (63). Out of 111 c-type cytochromes, 43 had no known homolog, and many were predicted to reside in the outer membrane. The large complement of outer membrane redox proteins in $G$. sulfurreducens became even more of an anomaly as the simpler electron transfer strategy of metal-reducing $S$. oneidensis emerged. If Shewanella requires only a single inner membrane cytochrome and a single outer membrane conduit to reduce a multitude of substrates $(36,39,40,53)$, why does Geobacter have so many cytochromes?

Evidence that more than one $G$. sulfurreducens outer membrane pathway exists for reduction of extracellular substrates accumulated in at least 11 separate studies since the discovery of $\operatorname{OmcB}(34,43,45)$. Deletion of $o m c B$ impacted Fe(III) reduction but had little effect on $U(I V)$ or $M n(I V)$ oxide reduction $(51,64)$. A $\triangle$ omcB suppressor strain that 
evolved for improved Fe(III) citrate growth still reduced Fe(III) oxides poorly (44). Strains lacking omcB grew similarly to the wild type on electrodes in four different studies (24, $29,57,65)$, and OmcB abundance was shown to be lowest on cells near electrodes (66). An insertional mutant lacking six secreted or outer membrane-associated cytochromes in addition to OmcB still demonstrated Fe(III) oxide reduction (67). After replacing the entire $o m C B C$ region with an antibiotic resistance cassette and still finding residual $\mathrm{Fe}$ (III) reduction ability, Liu et al. (45) speculated that other c-type cytochrome conduitlike clusters in the genome might be active. Most recently, transposon sequencing (Tn-seq) analysis of electrode-grown cells revealed little effect of omcB cluster mutations yet identified significant defects from insertions in unstudied clusters with c-type cytochrome features (46). This combined evidence led us to seek alternative conduit gene clusters that could address both the long-standing mystery of growth by omcB mutants and the complexity of electron transfer proteins in the Geobacter genome.

The genetic analysis presented here supports a role for these unstudied conduit gene clusters during extracellular respiration. All mutants still containing at least one cluster retained a partial ability to reduce metals, while deletion of all clusters-the entire om $B C$ region, plus all three ext clusters - finally was able to eliminate metal reduction. This overlapping function of some clusters helps explain the reported variability between laboratory strains and the rapid evolution of suppressors in $\triangle$ omcB mutants.

In the case of electrodes at both high and low potentials, only deletion of extABCD altered phenotypes. Additionally, a strain with only ext $A B C D$ remaining on the genome outperformed the wild type in terms of growth rate and final current density when grown on electrodes. Since expression of ext $A B C D$ was also able to restore reduction of the soluble acceptor Fe(III) citrate, this cluster can confer the phenotype of extracellular respiration under a condition where pili and secreted cytochromes are not known to be important, supporting the conclusion that ext $A B C D$ encodes proteins involved in electron transfer. Overall, these data show that for all tested metal acceptors, more than one conduit cluster is necessary for wild-type levels of reduction, any one cluster can support partial reduction of many metals, and only one cluster can be linked to electrode respiration.

Genetic analyses are typically a first step, designed to reveal which genes are necessary for a phenotype and worthy of further study. Biochemical and biophysical analyses will be needed to (i) prove if products of ext gene clusters indeed function as conduits to transfer electrons across the outer membrane and (ii) identify the proteins or metals these complexes interact with to explain why these clusters seem so tightly linked to growth with certain substrates. Expression analyses failed to detect large differences in ext or omcBC family genes during transitions between acceptors, arguing against changes in expression as an explanation for specificity. Our ability to complement growth with electrodes in the $\triangle 5$ mutant by expressing ext $A B C D$ from a vector, while the $o m c B$ conduit could not complement growth, further argues against expression differences causing these phenotypes. Unknown posttranscriptional events could be caused by the absence of different gene clusters, but the conclusion that these gene clusters are necessary remains the same.

To reduce metal particles or surfaces likely requires each membrane-bound complex to interact with extracellular proteins, such as OmcZ, OmcS, PgcA, or pili, to aid transfer of electrons to the final destination. If these partner proteins are not expressed or made available under all conditions, an outer membrane complex may not be capable of contributing to respiration. In the case of soluble metals such as Fe(III) citrate, conduit complexes should be able to directly reduce the acceptor, making apparent specificity more likely due to the ability of the complex(es) to interact with Fe(III) directly.

It is also important to consider lessons from insertional deletions in G. sulfurreducens, such as the diheme peroxidase MacA. MacA was initially hypothesized to be an inner membrane quinone oxioreductase, based on the defective phenotype of $\triangle$ macA mutants during $\mathrm{Fe}(\mathrm{III})$ citrate reduction (68); this phenotype was later explained by $\triangle$ macA mutants not expressing $o m c B$, as the $\triangle m a c A$ phenotype could be rescued by express- 
ing $\operatorname{omcB}$ from a vector $(69,70)$. As MacA is now known to instead be a soluble peroxidase, oxidative stress in early $\triangle m a c A$ mutants studied could have resulted in global downregulation of cytochromes. In our work, the availability of every combination of gene cluster deletion and acceptor condition allows many general downregulation hypotheses to be eliminated. For example, if deletion of ext $A B C D$ suppressed production of pili or cytochromes such as OmcS, all $\triangle$ ext $A B C D$ mutants would be predicted to show both electrode and metal oxide defects, which we did not observe.

Initial transcriptomic surveys also failed to find severe or off-target transcriptional effects on known electron transfer proteins from deletion of ombB-omaB-omcB-orfsombC-omaC-omcC, extEFG, or extHIJKL that could explain the enhanced growth of the ext $A B C D^{+}$mutant. The fact that only the ombB-omaB-omcB cluster was necessary to restore Fe(III) citrate reduction further indicated that orfS was not essential. However, all of these deletions removed many parts of the genome which were not tested for complementation by single genes, leaving open the possibility of regulatory interactions. Also, in a complex system such as this, posttranslational events such as polymerization of pilin monomers into filaments and extracellular cytochrome secretion could be affected by the absence of specific proteins under specific conditions. It is difficult to detect negative interactions via RNA-seq or proteomic analyses when mutants fail to grow, but such effects should be addressed in future suppressor and heterologous expression studies, now that these clusters have been identified.

Insights from similar gene clusters in related organisms. It remains difficult to predict any function for multiheme cytochromes based on sequence alone, so their genetic context may reveal other clues to their role and aid identification of such clusters in other genomes. None of the ext regions fits the pattern of the mtr 3-gene cytochrome conduit operon of genes for one small $(\sim 40-\mathrm{kDa})$ periplasmic cytochrome, an integral outer membrane protein, and one large $(>90-k D a)$ lipoprotein cytochrome. For example, ext $A B C D$ includes genes for two small lipoprotein cytochromes, extEFG is part of a hydrogenase family transcriptional unit, and extHIJKL contains the gene for a rhodanese-like lipoprotein instead of an extracellular cytochrome (Fig. 1).

Specifically, the transcriptional unit beginning with extEFG includes a homolog of YedY family periplasmic protein repair systems described for Escherichia coli (71), followed by the gene for an NiFe hydrogenase similar to bidirectional Hox hydrogenases used to recycle reducing equivalents in cyanobacteria (72-74). Rhodanase-like proteins related to ExtH typically are involved in sulfur metabolism (75-77), and an outer surface ExtH/rhodanese-like protein is linked to extracellular oxidation of metal sulfides by Acidithiobacillus ferrooxidans (78). Deletion of extl in G. sulfurreducens causes a severe defect in selenite and tellurite reduction (79). These links to metabolism of hydrogen, sulfur, and other oxyanions suggest roles outside metal reduction, and future genomic searches for electron conduit clusters should consider the possibility of noncytochrome components, such as FeS clusters, as the exposed lipoprotein.

Now that genes from ext operons can be used in searches of other genomes, an interesting pattern emerges in putative conduit regions throughout Desulfuromonadales strains isolated from freshwater, saline, subsurface, and fuel cell environments (Fig. 9). In about one-third of cases, an entire cluster is conserved intact, such as extABCD in Geobacter anodireducens, Geobacter soli, and Geobacter pickeringii (Fig. 9B). However, when differences exist, they are typically nonorthologous replacements of the outer surface lipoprotein, such as where extABC is followed by a new cytochrome in Geobacter metallireducens, Geoalkalibacter ferrihydriticus, and Desulfuromonas soudanensis. Conservation of the periplasmic cytochrome with replacement of the outer surface redox lipoprotein also occurs frequently in the omcB and extHIJKL clusters (Fig. $9 A$ and D). For example, of 18 extHIJKL regions, 10 contain a different extracellular rhodanese-like protein with extIJKL, each with less than $40 \%$ identity to extH. This remarkable variability in extracellular components, compared to conservation of periplasmic redox proteins, suggests much higher rates of gene transfer and replacement of domains that are exposed to electron acceptors and the external environment. 
Gene clusters with all products $>40 \%$ identical to G. sulfurreducens cluster
Gene clusters with one or more products $<40 \%$ identical

to G. sulfurreducens cluster

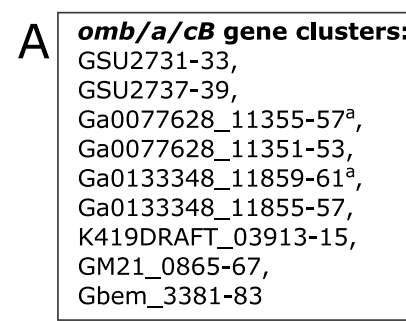

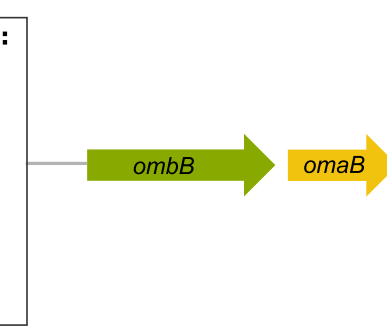

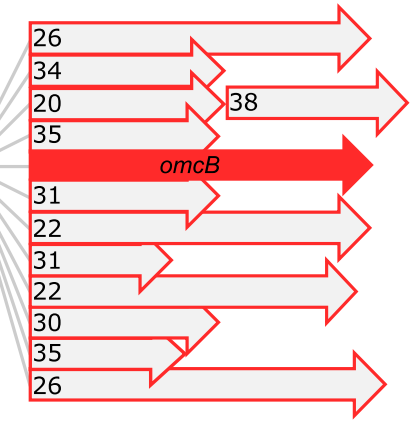

Geob_1684-1686

Geob_1680-1682

Gura_0991-0994

Gura_0987-0989

Ga0069501_112568-70

Ga0069501_112565-67a

Gmet_0911-13

Gmet_0908-10

Ga0052872_00317-19

Glov_2293-95

Ga0098289_101317-19

Ga0069501_112646-49

Gmet_0825-28

Ga0056053_00747-49

Ga0069009_11702-04

Ga0069009_112913-15

Ga0123695_112803-05 D888DRAFT_0826-8 N909DRAFT_2912-14 D888DRAFT_0811-13
C

\begin{tabular}{|l}
\hline extHIJKL gene clusters: \\
GSU2936-40, \\
Gbem_4028-32, \\
Ga0077628_112458-62, \\
K419DRAFT_02246-50, \\
Ga0133348_113069-73, \\
Geob_1336-41 \\
Gura_0444-48, \\
Gura_0450-54, \\
Gmet_0531-35, \\
GM21_4119-23
\end{tabular}
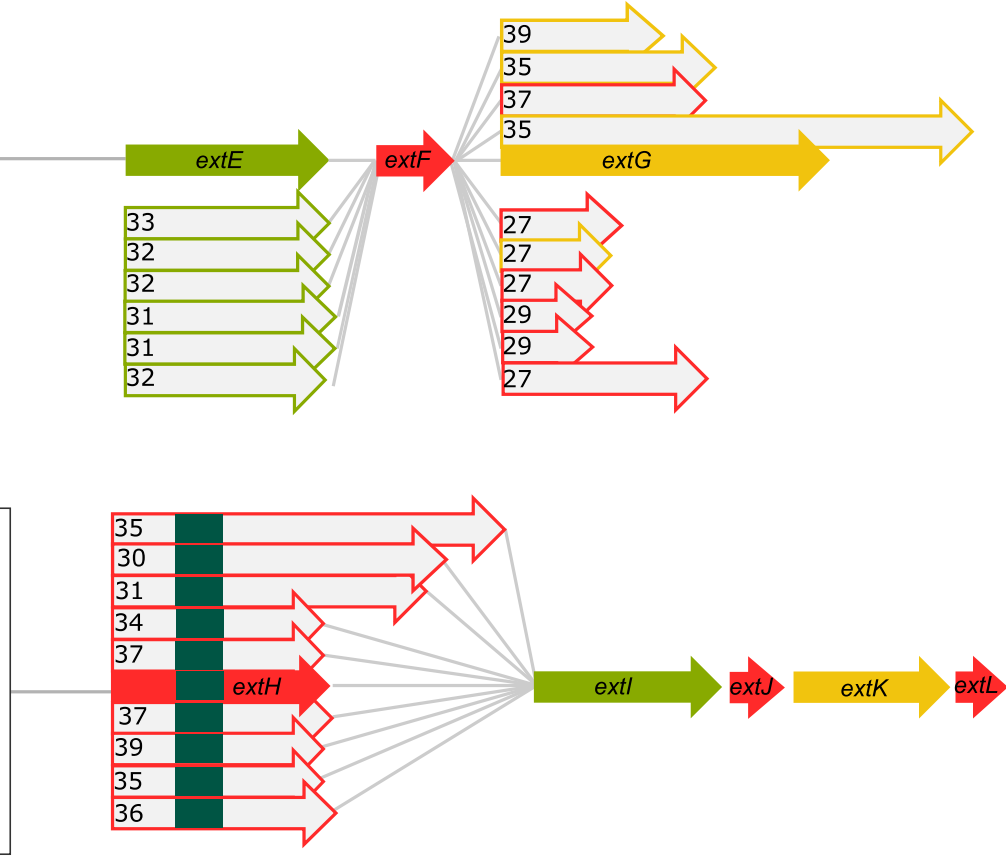

Gura 1837-39 Ga0052872_02630-32 Ga0098289_10179-81 Ga0052872_03679-81

GM21 0872-74 Gbem_3372-74 K419DRAFT 01592-94 GM18_3467-69 GM18_3461-63 Gfer_01407-09

FIG 9 Cytochrome conduit conservation across the order Desulfuromonodales. Shown is a representation of cytochrome conduit clusters from the Desulfuromonodales with homologs to either OmcBC (A), ExtABCD (B), ExtEFG (C), or ExtHIJKL (D). Complete clusters with all components sharing $>40 \%$ identity to the corresponding $G$. sulfurreducens cytochrome conduit are indicated in boxes to the left of each gene cluster. Clusters in which one or more proteins are replaced by a new element with $<40 \%$ identity are listed on the right side of each gene cluster. Numbers with proteins indicate the percent identity to the G. sulfurreducens version. Red arrows, putative outer membrane products with a predicted lipid attachment site; yellow arrows, predicted periplasmic components; green arrows, predicted outer membrane anchor components. Superscript letters a to d indicate the following: $a$, OmcBC homologs in these gene clusters also encode Hox hydrogenase complexes; $b$, gene clusters have contiguous extBCD loci but ext $A$ is not in the vicinity, as ext $A$ was found in separate parts of the genome for some of those organisms (see Table $\mathrm{S} 2$ in the supplemental material); $c$, the gene cluster has additional lipoprotein decaheme $c$-type cytochrome upstream of extE; $d$, lipid attachment sites corresponding to ExtJL could not be found, but there is an additional small lipoprotein encoded within the gene cluster. For ExtHIJKL clusters, homologs depicted above extH are found in gene clusters containing only extl, whereas homologs depicted below extH are found in gene clusters containing full extHIJKL loci. Upstream and on the opposite strand to all gene clusters homologous to extHIJKL there is a transcription regulator of the LysR family, except where marked by superscript letter e, where there is no transcriptional regulator in that region, and superscript letter $\mathrm{f}$, where there are transcriptional regulators of the TetR family instead. 
Summary. The data presented here significantly expand the number of genes encoding outer membrane redox proteins necessary during electron transfer in $G$. sulfurreducens and highlight a key difference in the Geobacter electron transfer strategy from those of other model organisms. In general, the pattern of multiple genes encoding seemingly overlapping or redundant roles is less like solitary respiratory reductases and more reminiscent of systems such as those of cellulolytic bacteria that produce numerous similar glucosidases to attack a constantly changing polysaccharide substrate $(36,40,59)$. A need for multiple outer membrane strategies could be a response to the complexity of metal oxides during reduction; minerals rapidly diversify to become multiphase assemblages of more crystalline phases, the cell-metal interface can become enriched in Fe(II), and organic materials can bind to alter the surface (80-82). Constitutively expressing an array of electron transfer pathways could make cells competitive at all stages with all electron acceptors, allowing Geobacter to outgrow more specialized organisms during rapid perturbations in the environment.

\section{MATERIALS AND METHODS}

Growth conditions. All experiments were performed with our laboratory strain of Geobacter sulfurreducens PCA as freshly streaked single colonies from freezer stocks. Anaerobic NB medium $(0.38$ $\mathrm{g} /$ liter $\mathrm{KCl}, 0.2 \mathrm{~g} /$ liter $\mathrm{NH}_{4} \mathrm{Cl}, 0.069 \mathrm{~g} /$ liter $\mathrm{NaH}_{2} \mathrm{PO}_{4} \cdot \mathrm{H}_{2} \mathrm{O}, 0.04 \mathrm{~g} /$ liter $\mathrm{CaCl}_{2} \cdot 2 \mathrm{H}_{2} \mathrm{O}, 0.2 \mathrm{~g} /$ liter $\mathrm{MgSO}_{4}$. $7 \mathrm{H}_{2} \mathrm{O}, 1 \%$ [vol/vol] trace mineral mix [pH 6.8] buffered with $2 \mathrm{~g} /$ liter $\mathrm{NaHCO}_{3}$ and flushed with 20:80 $\mathrm{N}_{2}-\mathrm{CO}_{2}$ gas mix) with $20 \mathrm{mM}$ acetate as the electron donor and $40 \mathrm{mM}$ fumarate as the electron acceptor was used to grow liquid cultures from colony picks. For metal reduction assays, $20 \mathrm{mM}$ acetate was added with either $55 \mathrm{mM}$ Fe(III) citrate, $\sim 20 \mathrm{mM}$ birnessite [Mn(IV) oxide], or $\sim 70 \mathrm{mM} \mathrm{Fe(III)} \mathrm{oxide} \mathrm{freshly}$ precipitated from $\mathrm{FeCl}_{2}$ by addition of $\mathrm{NaOH}$ and incubation at $\mathrm{pH} 7$ for $1 \mathrm{~h}$ before washing in deionized (DI) water. $\mathrm{Fe}(\mathrm{III})$ oxide medium contained an increased concentration of $0.6 \mathrm{~g} / \mathrm{liter} \mathrm{NaH}_{2} \mathrm{PO}_{4} \cdot \mathrm{H}_{2} \mathrm{O}$ to prevent further crystallization of the metal after autoclaving. All experiments were carried out at $30^{\circ} \mathrm{C}$.

Deletion and complementation construction. Putative conduits were identified through a genomic search for gene clusters containing loci predicted to encode a $\beta$-barrel using PRED-TMBB (49), contiguous to periplasmic and extracellular multiheme c-type cytochromes or other redox proteins. Localization was predicted by comparing PSORT (48) and the presence or absence of lipid attachment sites (50). Constructs to delete each gene cluster were designed to recombine to leave the site marker free and also nonpolar when located in larger transcriptional units, with most primers and plasmids for the single deletions described by Chan et al. (46). When genes were part of a larger transcriptional unit or contained an upstream promoter, the genes were left intact. For example, in the case of the omcBC cluster the transcriptional regulator orfR (GSU2741) was left intact, and in extEFG the promoter and untranslated region were left intact so as to not disrupt the downstream loci.

For deletion mutant construction, the suicide vector pK18mobsacB (83) with $\sim 750$ bp flanking the target region was used to induce homologous recombination as previously described (56). Briefly, two rounds of homologous recombination were selected for. The first selection used kanamycin resistance to select for mutants with the plasmid inserted into either the up- or downstream region, and the second selection used sucrose sensitivity to select for mutants that recombine the plasmid out of the chromosome, resulting in either the wild type or complete deletion mutants. Deletion mutants were identified using a kanamycin sensitivity test and verified by PCR amplification targeting the region. Multiple PCR amplifications with primers in different regions were used to confirm full deletion of each gene cluster (55) (see Table S1 in the supplemental material).

During this work, we found that manipulations in the omcBC cluster, which harbors large regions of $100 \%$ identity, frequently underwent recombination into unexpected hybrid mutants which could escape routine PCR verification. For example, when omaB and omaC genes recombined, a large hybrid operon containing omaB linked to ombC-omcC would result, and sometimes the region would recombine to produce a hybrid of the two repressors controlling expression of the region. Routine primer screening, especially targeting flanking regions, failed to detect the large product. Only via use of multiple internal primers (55) (Table S1), paired with longer-read or single molecule (PacBio) sequencing, were we able to verify and isolate strains in which complete loss of the omcBC cluster occurred and dispose of hybrid mutants. Whole-genome resequencing was also performed on strains containing only one cluster, such as the strain containing only ext $A B C D$, especially since this strain has an unexpected phenotype in which it produced more current than the wild type. Because these hybrid omcBC operon strains still contained mixed conduits and had altered expression due to disruption of the repressors upstream, verification by PCR and whole-genome sequencing (especially with single-molecule techniques able to span the entire $\sim 10$-kb region) is recommended to confirm deletions of large and repetitive regions, such as the omcBC cluster, when working with this region.

Mutants lacking a single gene region were used as parent strains to build additional mutations. In this manner, six double-gene-cluster-deletion mutants, four triple-cluster-deletion mutants, and one quintuple-cluster-deletion mutant lacking up to 19 genes were constructed (Fig. 1; Table 2). For complementation strains, putative conduits were amplified using primers listed in Table S1 and inserted into the G. sulfurreducens expression vector pRK2-Geo2 (56), which contains constitutive promoter $\mathrm{P}_{a c p p}$. The putative conduit ext $A B C D$ was assembled into a single transcriptional unit to ensure expression. 
TABLE 2 Strains and plasmids used in this study

\begin{tabular}{|c|c|c|}
\hline Strains or plasmid & Description or relevant genotype & Reference or source \\
\hline \multicolumn{3}{|c|}{$\begin{array}{l}\text { Geobacter sulfurreducens } \\
\text { strains }\end{array}$} \\
\hline DB1279 & $\triangle \mathrm{GSU} 2731-\mathrm{GSU} 2739(\triangle \mathrm{omcBC})$ & 46 \\
\hline DB1281 & $\Delta$ GSU2940-GSU2936 (DextHIJKL) & 46 \\
\hline DB1282 & $\Delta G S U 2724-G S U 2726(\triangle e x t E F G)$ & 46 \\
\hline DB1487 & $\triangle$ GSU2731-GSU2739 $\triangle$ GSU2645-GSU2642 ( $\triangle$ omcBC $\triangle \operatorname{ext} A B C D)$ & This study \\
\hline DB1489 & $\Delta$ GSU2645-GSU2642 $\triangle$ GSU2724-GSU2726 ( $\triangle$ extABCD $\triangle$ extEFG) & This study \\
\hline DB1490 & $\Delta$ GSU2645-GSU2642 $\Delta$ GSU2940-GSU2936 ( $\triangle$ extABCD $\triangle$ extHIJKL) & This study \\
\hline DB1290 & $\Delta$ GSU2731-GSU2739 $\triangle$ GSU2940-GSU2936 $\Delta$ GSU2724-GSU2726 (extABCD $\left.{ }^{+}\right)$ & This study \\
\hline DB1291 & 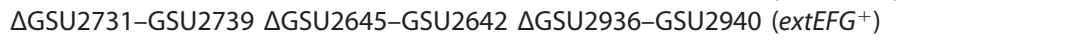 & This study \\
\hline DB1491 & AGSU2731-GSU2739 $\Delta$ GSU2645-GSU2642 $\Delta$ GSU2726-GSU2724 (extHIJKL $\left.{ }^{+}\right)$ & This study \\
\hline DB1492 & 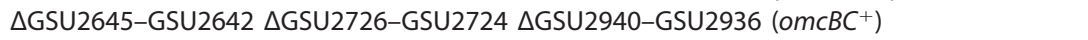 & This study \\
\hline DB1493 & 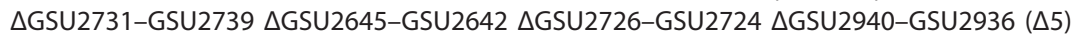 & This study \\
\hline pK18mobsacB & & 83 \\
\hline pRK2-Geo2 & & 56 \\
\hline pDomcBC & Flanking regions of omcBC in pK18mobsacB & This study \\
\hline $\mathrm{pDext} A B C D$ & Flanking regions of extABCD in pK18mobsacB & This study \\
\hline pDextEFG & Flanking regions of extEFG in pK18mobsacB & This study \\
\hline pDextHIJKL & Flanking regions of extHIJKL in pK18mobsacB & This study \\
\hline pomcB & ombB-omaB-omcB in pRK2-Geo2 & This study \\
\hline pext $A B C D$ & ext $A B C D$ in $\mathrm{pRK} 2-\mathrm{Geo} 2$ & This study \\
\hline
\end{tabular}

Electrode reduction assays. Sterile three-electrode conical reactors containing $15 \mathrm{ml} \mathrm{NB}$ medium with $40 \mathrm{mM}$ acetate as the electron donor and $50 \mathrm{mM} \mathrm{NaCl}$ to equilibrate the salt concentration were flushed with a mix of $\mathrm{N}_{2}-\mathrm{CO}_{2}$ gas $(80: 20[\mathrm{vol} / \mathrm{vol}])$ until the $\mathrm{O}_{2}$ concentration reached less than $2 \mathrm{ppm}$. Liquid cultures were prepared by inoculating 1-ml liquid cultures from single colonies inside an anaerobic chamber. Once these cultures reached late exponential to stationary phase, they were used to inoculate $10-\mathrm{ml}$ cultures with $10 \%$ ( $\mathrm{vol} / \mathrm{vol})$. Each reactor was then inoculated with $25 \%$ (vol/vol) from this liquid culture as it approached acceptor limitation, at an optical density at $600 \mathrm{~nm}\left(\mathrm{OD}_{600}\right)$ between 0.48 and 0.52 . Working electrodes were set at either $-0.1 \mathrm{~V}$ or $+0.24 \mathrm{~V}$ versus SHE, and average current density was recorded every $12 \mathrm{~s}$. Each liquid culture propagated from an individual colony pick served no more than two reactors, and at least three separate colonies were picked for all electrode reduction experiments for a total of $\geq 3$ biological replicates.

Metal reduction assays. NB medium with $20 \mathrm{mM}$ acetate as the electron donor and either $55 \mathrm{mM}$

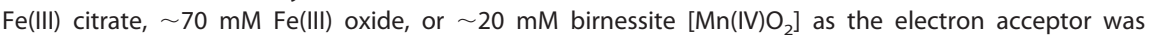
inoculated with a $0.1 \%$ inoculum of early-stationary-phase fumarate-limited cultures. Samples were taken as necessary with anaerobic and sterile needles. These were diluted 1:10 into $0.5 \mathrm{~N} \mathrm{HCl}$ for the Fe(III) samples and into $2 \mathrm{~N} \mathrm{HCl}-4 \mathrm{mM} \mathrm{FeSO}_{4}$ for $\mathrm{Mn}$ (IV) samples. Samples were diluted once more by 1:10 in the case of $\mathrm{Fe}(\mathrm{III})$ assays and by $1: 5$ in the case of $\mathrm{Mn}(\mathrm{IV})$ assays into $0.5 \mathrm{~N} \mathrm{HCl}$. FerroZine reagent was then used to determine the $\mathrm{Fe}$ (II) concentration in each sample. Original Fe(II) concentrations were calculated for Fe(III) reduction assays by accounting for dilutions, and original $\mathrm{Mn}(\mathrm{IV})$ concentrations were calculated by accounting for the concentration of Fe(II) oxidized by $\mathrm{Mn}(\mathrm{IV})$ based on the following: $\mathrm{Mn}(\mathrm{IV})+2 \mathrm{Fe}(\mathrm{II})=$ $\mathrm{Mn}(\mathrm{II})+2 \mathrm{Fe}$ (III). In other words, two molecules of Fe(II) are reduced by one molecule of $\mathrm{Mn}(\mathrm{IV})$. Therefore, the increase of $\mathrm{Fe}(\mathrm{II})$ concentration over time in our samples indicates a decrease of $\mathrm{Mn}(\mathrm{IV})$, or increase of $\mathrm{Mn}(\mathrm{II})$, in a 2:1 ratio.

RNA-seq. For liquid-grown cultures, total RNA was extracted from $10 \mathrm{ml}$ G. sulfurreducens culture grown to mid-log phase $\left(\mathrm{OD}_{600}\right.$ of 0.25 to 0.3$)$. For biofilm-grown cultures, total RNA was extracted from graphite electrodes of $G$. sulfurreducens biofilms grown to mid-log phase $\left(300 \mu \mathrm{A} / \mathrm{cm}^{2}\right)$. Biofilms were rinsed to remove planktonic cells and removed from electrodes using a plastic spatula. Cell pellets from all samples were washed in RNAprotect (Qiagen) and frozen at $-80^{\circ} \mathrm{C}$ before RNA extraction using RNeasy with on-column DNase treatment (Qiagen). rRNA was depleted using RiboZero (Illumina) by the University of Minnesota Genomics Center before stranded synthesis and sequenced on Illumina HiSeq 2500 in 125-bp pair-ended mode. Residual rRNA sequences were removed before analysis using Rockhopper (84). Duplicate biological samples were analyzed for each strain. An in-house resequenced G. sulfurreducens genome and annotation released in a prior publication were used as reference $(46,56)$. Full RPKM values are in Table S2.

Homolog search and alignment. Homologs to each of the individual cytochrome conduit proteins were queried on 30 November 2016 in the Integrated Microbial Genomes database (85) with a cutoff of $75 \%$ sequence length and $40 \%$ identity based on amino acid sequence within the Desulfuromonadales. 
A higher percent identity was demanded in this search due to the high heme binding site density with the invariable $\mathrm{CXXCH}$ sequence. Only ExtJ and ExtL were excluded from the search, and the OmcBC region was collapsed into a single cluster due to the high identity shared between the two copies. The gene neighborhood around each homolog hit was analyzed. With a few exceptions (see Table S2), all homologs were found to be conserved in gene clusters predicted to encode cytochrome conduits and containing several additional homologs to each corresponding $G$. sulfurreducens conduit. The proteins within each homologous cytochrome conduit that did not fall within the set cutoff were aligned to the amino acid sequence of the $G$. sulfurreducens component they replaced using Clustal $\Omega$ (86).

Accession number(s). Raw RNA-seq reads are deposited in the NCBI SRA under BioProject accession number PRJNA290373.

\section{SUPPLEMENTAL MATERIAL}

Supplemental material for this article may be found at https://doi.org/10.1128/JB .00347-18.

SUPPLEMENTAL FILE 1, PDF file, 0.7 MB.
SUPPLEMENTAL FILE 2, XLSX file, $0.4 \mathrm{MB}$.
SUPPLEMENTAL FILE 3, XLSX file, $0.1 \mathrm{MB}$.

\section{ACKNOWLEDGMENTS}

We thank J. Badalamenti for sequence analysis assistance and data management. This research was supported by the Office of Naval Research (N000141210308). F.J.O. is supported by the National Council of Science and Technology of Mexico (CONACYT).

\section{REFERENCES}

1. Tadanier CJ, Schreiber ME, Roller JW. 2005. Arsenic mobilization through microbially mediated deflocculation of ferrihydrite. Environ Sci Technol 39:3061-3068. https://doi.org/10.1021/es048206d.

2. N'Guessan AL, Vrionis HA, Resch CT, Long PE, Lovley DR. 2008. Sustained removal of uranium from contaminated groundwater following stimulation of dissimilatory metal reduction. Environ Sci Technol 42: 2999-3004. https://doi.org/10.1021/es071960p.

3. Toner BM, Fakra SC, Manganini SJ, Santelli CM, Marcus MA, Moffett JW, Rouxel O, German CR, Edwards KJ. 2009. Preservation of iron(II) by carbon-rich matrices in a hydrothermal plume. Nat Geosci 2:197-201. https://doi.org/10.1038/ngeo433.

4. Williams $K \mathrm{H}$, Long $\mathrm{PE}$, Davis JA, Wilkins $\mathrm{MJ}, \mathrm{N}^{\prime}$ Guessan $\mathrm{AL}$, Steefel $\mathrm{Cl}$, Yang L, Newcomer D, Spane FA, Kerkhof LJ, McGuinness L, Dayvault R, Lovley DR. 2011. Acetate availability and its influence on sustainable bioremediation of uranium-contaminated groundwater. Geomicrobiol J 28:519-539. https://doi.org/10.1080/01490451.2010.520074.

5. Yelton AP, Williams KH, Fournelle J, Wrighton KC, Handley KM, Banfield JF. 2013. Vanadate and acetate biostimulation of contaminated sediments decreases diversity, selects for specific taxa, and decreases aqueous V5+ soncentration. Environ Sci Technol 47:6500-6509. https://doi .org/10.1021/es4006674.

6. Couture R-M, Charlet L, Markelova E, Madé B, Parsons CT. 2015. On-off mobilization of contaminants in soils during redox oscillations. Environ Sci Technol 49:3015-3023. https://doi.org/10.1021/es5061879.

7. Bond DR, Holmes DE, Tender LM, Lovley DR. 2002. Electrode-reducing microorganisms that harvest energy from marine sediments. Science 295:483-485. https://doi.org/10.1126/science.1066771.

8. Bond DR, Lovley DR. 2003. Electricity production by Geobacter sulfurreducens attached to electrodes. Appl Environ Microbiol 69:1548-1555. https://doi.org/10.1128/AEM.69.3.1548-1555.2003.

9. Holmes DE, Bond DR, O'Neil RA, Reimers CE, Tender LR, Lovley DR. 2004 Microbial communities associated with electrodes harvesting electricity from a variety of aquatic sediments. Microb Ecol 48:178-190. https:// doi.org/10.1007/s00248-003-0004-4.

10. Ren Z, Steinberg LM, Regan JM. 2008. Electricity production and microbial biofilm characterization in cellulose-fed microbial fuel cells. Water Sci Technol 58:617-622. https://doi.org/10.2166/wst.2008.431.

11. Logan BE, Rabaey K. 2012. Conversion of wastes into bioelectricity and chemicals by using microbial electrochemical technologies. Science 337: 686-690. https://doi.org/10.1126/science.1217412.

12. Schrader PS, Reimers CE, Girguis P, Delaney J, Doolan C, Wolf M, Green D. 2016. Independent benthic microbial fuel cells powering sensors and acoustic communications with the MARS underwater observatory. J
Atmos Ocean Technol 33:607-617. https://doi.org/10.1175/JTECH-D-15 -0102.1.

13. Schievano A, Pepé Sciarria T, Vanbroekhoven K, De Wever H, Puig S, Andersen SJ, Rabaey K, Pant D. 2016. Electro-fermentation-merging electrochemistry with fermentation in industrial applications. Trends Biotechnol 34:866-878. https://doi.org/10.1016/j.tibtech.2016.04.007.

14. Gralnick JA, Newman DK. 2007. Extracellular respiration. Mol Microbiol 65:1-11. https://doi.org/10.1111/j.1365-2958.2007.05778.x.

15. Shi L, Dong H, Reguera G, Beyenal H, Lu A, Liu J, Yu H-Q, Fredrickson JK. 2016. Extracellular electron transfer mechanisms between microorganisms and minerals. Nat Rev Microbiol 14:651-662. https://doi.org/10 .1038/nrmicro.2016.93.

16. Navrotsky A, Mazeina L, Majzlan J. 2008. Size-driven structural and thermodynamic complexity in iron oxides. Science 319:1635-1638. https://doi.org/10.1126/science.1148614.

17. Majzlan J. 2013. Minerals and aqueous species of iron and manganese as reactants and products of microbial metal respiration, p 1-28. In Gescher J, Kappler A (ed), Microbial metal respiration. Springer, Berlin, Germany.

18. Levar CE, Hoffman CL, Dunshee AJ, Toner BM, Bond DR. 2017. Redox potential as a master variable controlling pathways of metal reduction by Geobacter sulfurreducens. ISME J 11:741-752. https://doi.org/10.1038/ ismej.2016.146.

19. Marsili E, Sun J, Bond DR. 2010. Voltammetry and growth physiology of Geobacter sulfurreducens biofilms as a function of growth stage and imposed electrode potential. Electroanalysis 22:865-874. https://doi .org/10.1002/elan.200800007.

20. Snider RM, Strycharz-Glaven SM, Tsoi SD, Erickson JS, Tender LM. 2012. Long-range electron transport in Geobacter sulfurreducens biofilms is redox gradient-driven. Proc Natl Acad Sci U S A 109:15467-15472. https://doi.org/10.1073/pnas.1209829109.

21. Robuschi L, Tomba JP, Schrott GD, Bonanni PS, Desimone PM, Busalmen JP. 2013. Spectroscopic slicing to reveal internal redox gradients in electricity-producing biofilms. Angew Chem Int Ed Engl 52:925-928. https://doi.org/10.1002/anie.201205440.

22. Zacharoff L, Chan CH, Bond DR. 2016. Reduction of low potential electron acceptors requires the $\mathrm{CbcL}$ inner membrane cytochrome of Geobacter sulfurreducens. Bioelectrochemistry 107:7-13. https://doi.org/10 .1016/j.bioelechem.2015.08.003.

23. Levar CE, Chan CH, Mehta-Kolte MG, Bond DR. 2014. An inner membrane cytochrome required only for reduction of high redox potential extracellular electron acceptors. mBio 5:e02034-14. https://doi.org/10.1128/ mBio.02034-14.

24. Nevin KP, Kim B-C, Glaven RH, Johnson JP, Woodard TL, Methé BA, DiDonato RJ, Jr, Covalla SF, Franks AE, Liu A, Lovley DR. 2009. Anode 
biofilm transcriptomics reveals outer surface components essential for high density current production in Geobacter sulfurreducens fuel cells. PLoS One 4:e5628. https://doi.org/10.1371/journal.pone.0005628.

25. Leang C, Qian X, Mester T, Lovley DR. 2010. Alignment of the c-type cytochrome OmcS along pili of Geobacter sulfurreducens. Appl Environ Microbiol 76:4080-4084. https://doi.org/10.1128/AEM.00023-10.

26. Tremblay P-L, Summers ZM, Glaven RH, Nevin KP, Zengler K, Barrett CL, Qiu Y, Palsson BO, Lovley DR. 2011. A c-type cytochrome and a transcriptional regulator responsible for enhanced extracellular electron transfer in Geobacter sulfurreducens revealed by adaptive evolution.EnvironMicrobiol13:13-23.https://doi.org/10.1111/j.1462-2920. 2010.02302.x.

27. Qian X, Mester T, Morgado L, Arakawa T, Sharma ML, Inoue K, Joseph C, Salgueiro CA, Maroney MJ, Lovley DR. 2011. Biochemical characterization of purified OmcS, a c-type cytochrome required for insoluble Fe(III) reduction in Geobacter sulfurreducens. Biochim Biophys Acta 1807: 404-412. https://doi.org/10.1016/j.bbabio.2011.01.003.

28. Smith JA, Tremblay P-L, Shrestha PM, Snoeyenbos-West OL, Franks AE, Nevin KP, Lovley DR. 2014. Going wireless: Fe(III) oxide reduction without pili by Geobacter sulfurreducens strain JS-1. Appl Environ Microbiol 80:4331-4340. https://doi.org/10.1128/AEM.01122-14.

29. Peng L, Zhang Y. 2017. Cytochrome OmcZ is essential for the current generation by Geobacter sulfurreducens under low electrode potential. Electrochim Acta 228:447-452. https://doi.org/10.1016/j.electacta.2017 .01.091.

30. Zacharoff LA, Morrone D, Bond DR. 2017. Geobacter sulfurreducens extracellular multiheme cytochrome PgcA facilitates respiration to Fe(III) oxides but not electrodes. Front Microbiol 8:2481. https://doi.org/10 .3389/fmicb.2017.02481.

31. Reguera G, Nevin KP, Nicoll JS, Covalla SF, Woodard TL, Lovley DR. 2006. Biofilm and nanowire production leads to increased current in Geobacter sulfurreducens fuel cells. Appl Environ Microbiol 72:7345-7348. https:// doi.org/10.1128/AEM.01444-06.

32. Richardson DJ, Butt JN, Fredrickson JK, Zachara JM, Shi L, Edwards MJ, White G, Baiden N, Gates AJ, Marritt SJ, Clarke TA. 2012. The "porincytochrome" model for microbe-to-mineral electron transfer. Mol Microbiol 85:201-212. https://doi.org/10.1111/j.1365-2958.2012.08088.x.

33. Shi L, Fredrickson JK, Zachara JM. 2014. Genomic analyses of bacterial porin-cytochrome gene clusters. Front Microbiol 5:657. https://doi.org/ 10.3389/fmicb.2014.00657.

34. Liu Y, Wang Z, Liu J, Levar C, Edwards MJ, Babauta JT, Kennedy DW, Shi Z, Beyenal H, Bond DR, Clarke TA, Butt JN, Richardson DJ, Rosso KM, Zachara JM, Fredrickson JK, Shi L. 2014. A trans-outer membrane porincytochrome protein complex for extracellular electron transfer by Geobacter sulfurreducens PCA. Environ Microbiol Rep 6:776-785. https://doi .org/10.1111/1758-2229.12204.

35. Hartshorne RS, Reardon CL, Ross D, Nuester J, Clarke TA, Gates AJ, Mills PC, Fredrickson JK, Zachara JM, Shi L, Beliaev AS, Marshall MJ, Tien M, Brantley S, Butt JN, Richardson DJ. 2009. Characterization of an electron conduit between bacteria and the extracellular environment. Proc Natl Acad Sci U S A 106:22169-22174. https://doi.org/10 .1073/pnas.0900086106.

36. Wang Z, Liu C, Wang X, Marshall MJ, Zachara JM, Rosso KM, Dupuis M, Fredrickson JK, Heald S, Shi L. 2008. Kinetics of reduction of $\mathrm{Fe}(\mathrm{III})$ complexes by outer membrane cytochromes MtrC and OmcA of Shewanella oneidensis MR-1. Appl Environ Microbiol 74:6746-6755. https:// doi.org/10.1128/AEM.01454-08.

37. Coursolle D, Gralnick JA. 2012. Reconstruction of extracellular respiratory pathways for iron(III) reduction in Shewanella oneidensis strain MR-1. Front Microbiol 3:56. https://doi.org/10.3389/fmicb.2012.00056.

38. White GF, Shi Z, Shi L, Wang Z, Dohnalkova AC, Marshall MJ, Fredrickson JK, Zachara JM, Butt JN, Richardson DJ, Clarke TA. 2013. Rapid electron exchange between surface-exposed bacterial cytochromes and Fe(III) minerals. Proc Natl Acad Sci U S A 110:6346-6351. https://doi.org/10 $.1073 /$ pnas. 1220074110 .

39. Baron D, LaBelle E, Coursolle D, Gralnick JA, Bond DR. 2009. Electrochemical measurement of electron transfer kinetics by Shewanella oneidensis MR-1. J Biol Chem 284:28865-28873. https://doi.org/10.1074/jbc M109.043455.

40. Coursolle D, Baron DB, Bond DR, Gralnick JA. 2010. The Mtr respiratory pathway is essential for reducing flavins and electrodes in Shewanella oneidensis. J Bacteriol 192:467-474. https://doi.org/10.1128/JB.00925-09.

41. Gralnick JA, Vali H, Lies DP, Newman DK. 2006. Extracellular respiration of dimethyl sulfoxide by Shewanella oneidensis strain MR-1. Proc
Natl Acad Sci U S A 103:4669-4674. https://doi.org/10.1073/pnas .0505959103 .

42. Jiao Y, Newman DK. 2007. The pio operon is essential for phototrophic $\mathrm{Fe}(\mathrm{II})$ oxidation in Rhodopseudomonas palustris TIE-1. J Bacteriol 189: 1765-1773. https://doi.org/10.1128/JB.00776-06.

43. Leang C, Coppi MV, Lovley DR. 2003. OmcB, a c-type polyheme cytochrome, involved in $\mathrm{Fe}(\mathrm{III})$ reduction in Geobacter sulfurreducens. J Bacteriol 185:2096-2103. https://doi.org/10.1128/JB.185.7.2096-2103.2003.

44. Leang C, Lovley DR. 2005. Regulation of two highly similar genes, omc $B$ and omcC, in a $10 \mathrm{~kb}$ chromosomal duplication in Geobacter sulfurreducens. Microbiology 151:1761-1767. https://doi.org/10.1099/ mic.0.27870-0.

45. Liu Y, Fredrickson JK, Zachara JM, Shi L. 2015. Direct involvement of $o m b B$, omaB, and $o m c B$ genes in extracellular reduction of Fe(III) by Geobacter sulfurreducens PCA. Front Microbiol 6:1075. https://doi.org/10 .3389/fmicb.2015.01075.

46. Chan CH, Levar CE, Jiménez Otero F, Bond DR. 2017. Genome scale mutational analysis of Geobacter sulfurreducens reveals distinct molecular mechanisms for respiration and sensing of poised electrodes versus Fe(III) oxides. J Bacteriol 199:e00340-17. https://doi.org/10 $.1128 / \mathrm{JB} .00340-17$.

47. Jiménez Otero F, Bond DR. 2017. Gene clusters encoding putative outer membrane electron conduits have specific roles during metal and electrode respiration in Geobacter sulfurreducens. bioRxiv https://doi.org/10 $.1101 / 169086$

48. Yu NY, Wagner JR, Laird MR, Melli G, Rey S, Lo R, Dao P, Sahinalp SC, Ester M, Foster LJ, Brinkman FSL. 2010. PSORTb 3.0: improved protein subcelIular localization prediction with refined localization subcategories and predictive capabilities for all prokaryotes. Bioinformatics 26:1608-1615. https://doi.org/10.1093/bioinformatics/btq249.

49. Bagos PG, Liakopoulos TD, Spyropoulos IC, Hamodrakas SJ. 2004. PRED-TMBB: a web server for predicting the topology of $\beta$-barrel outer membrane proteins. Nucleic Acids Res 32:W400-W404. https:// doi.org/10.1093/nar/gkh417.

50. Juncker AS, Willenbrock $H$, von Heijne $G$, Brunak S, Nielsen $H$, Krogh A. 2003. Prediction of lipoprotein signal peptides in Gram-negative bacteria. Protein Sci 12:1652-1662. https://doi.org/10.1110/ps.0303703.

51. Aklujkar M, Coppi MV, Leang C, Kim BC, Chavan MA, Perpetua LA, Giloteaux L, Liu A, Holmes DE. 2013. Proteins involved in electron transfer to Fe(III) and Mn(IV) oxides by Geobacter sulfurreducens and Geobacter uraniireducens. Microbiology 159:515-535. https://doi.org/10 .1099/mic.0.064089-0.

52. Fujita M, Mihara H, Goto S, Esaki N, Kanehisa M. 2007. Mining prokaryotic genomes for unknown amino acids: a stop-codon-based approach. BMC Bioinformatics 8:225. https://doi.org/10.1186/1471-2105-8-225.

53. Coursolle D, Gralnick JA. 2010. Modularity of the Mtr respiratory pathway of Shewanella oneidensis strain MR-1. Mol Microbiol 77:995-1008.

54. Clarke TA, Edwards MJ, Gates AJ, Hall A, White GF, Bradley J, Reardon CL, Shi L, Beliaev AS, Marshall MJ, Wang Z, Watmough NJ, Fredrickson JK, Zachara JM, Butt JN, Richardson DJ. 2011. Structure of a bacterial cell surface decaheme electron conduit. Proc Natl Acad Sci U S A 108: 9384-9389. https://doi.org/10.1073/pnas.1017200108.

55. Edwards MJ, Hall A, Shi L, Fredrickson JK, Zachara JM, Butt JN, Richardson DJ, Clarke TA. 2012. The crystal structure of the extracellular 11heme cytochrome UndA reveals a conserved 10-heme motif and defined binding site for soluble iron chelates. Structure 20:1275-1284. https:// doi.org/10.1016/j.str.2012.04.016.

56. Chan CH, Levar CE, Zacharoff L, Badalamenti JP, Bond DR. 2015. Scarless genome editing and stable inducible expression vectors for Geobacter sulfurreducens. Appl Environ Microbiol 81:7178-7186. https://doi.org/10 .1128/AEM.01967-15.

57. Holmes DE, Chaudhuri SK, Nevin KP, Mehta T, Methé BA, Liu A, Ward JE, Woodard TL, Webster J, Lovley DR. 2006. Microarray and genetic analysis of electron transfer to electrodes in Geobacter sulfurreducens. Environ Microbiol 8:1805-1815. https://doi.org/10.1111/j.1462-2920.2006.01065.x.

58. Bonanni PS, Bradley DF, Schrott GD, Busalmen JP. 2013. Limitations for current production in Geobacter sulfurreducens biofilms. ChemSusChem 6:711-720. https://doi.org/10.1002/cssc.201200671.

59. Nelson CE, Rogowski A, Morland C, Wilhide JA, Gilbert HJ, Gardner JG. 2017. Systems analysis in Cellvibrio japonicus resolves predicted redundancy of $\beta$-glucosidases and determines essential physiological functions. Mol Microbiol 104:294-305. https://doi.org/10.1111/mmi.13625.

60. Juárez K, Kim B-C, Nevin K, Olvera L, Reguera G, Lovley DR, Methé BA. 2009. PilR, a transcriptional regulator for pilin and other genes required 
for Fe(III) reduction in Geobacter sulfurreducens. J Mol Microbiol Biotechnol 16:146-158. https://doi.org/10.1159/000115849.

61. Steidl RJ, Lampa-Pastirk S, Reguera G. 2016. Mechanistic stratification in electroactive biofilms of Geobacter sulfurreducens mediated by pilus nanowires. Nat Commun 7:12217. https://doi.org/10.1038/ncomms12217.

62. Kim B-C, Leang C, Ding Y-HR, Glaven RH, Coppi MV, Lovley DR. 2005. OmcF, a putative c-type monoheme outer membrane cytochrome required for the expression of other outer membrane cytochromes in Geobacter sulfurreducens. J Bacteriol 187:4505-4513. https://doi.org/10 .1128/JB.187.13.4505-4513.2005.

63. Methé BA, Nelson KE, Eisen JA, Paulsen IT, Nelson W, Heidelberg JF, Wu D, Wu M, Ward N, Beanan MJ, Dodson RJ, Madupu R, Brinkac LM, Daugherty SC, DeBoy RT, Durkin AS, Gwinn M, Kolonay JF, Sullivan SA, Haft DH, Selengut J, Davidsen TM, Zafar N, White O, Tran B, Romero C, Forberger HA, Weidman J, Khouri H, Feldblyum TV, Utterback TR, Aken SEV, Lovley DR, Fraser CM. 2003. Genome of Geobacter sulfurreducens: metal reduction in subsurface environments. Science 302:1967-1969. https://doi.org/10.1126/science.1088727.

64. Shelobolina ES, Coppi MV, Korenevsky AA, DiDonato LN, Sullivan SA, Konishi H, Xu H, Leang C, Butler JE, Kim B-C, Lovley DR. 2007. Importance of c-type cytochromes for $\mathrm{U}(\mathrm{VI})$ reduction by Geobacter sulfurreducens. BMC Microbiol 7:16. https://doi.org/10.1186/1471-2180-7-16.

65. Richter H, Nevin PK, Jia H, Lowy AD, Lovley RD, Tender ML. 2009. Cyclic voltammetry of biofilms of wild type and mutant Geobacter sulfurreducens on fuel cell anodes indicates possible roles of OmcB, OmcZ, type IV pili, and protons in extracellular electron transfer. Energy Environ Sci 2:506-516. https://doi.org/10.1039/b816647a.

66. Stephen CS, LaBelle EV, Brantley SL, Bond DR. 2014. Abundance of the multiheme c-type cytochrome OmcB increases in outer biofilm layers of electrode-grown Geobacter sulfurreducens. PLoS One 9:e104336. https:// doi.org/10.1371/journal.pone.0104336.

67. Ueki T, DiDonato LN, Lovley DR. 2017. Toward establishing minimum requirements for extracellular electron transfer in Geobacter sulfurreducens. FEMS Microbiol Lett 364:fnx093. https://doi.org/10.1093/femsle/ fnx093.

68. Butler JE, Kaufmann F, Coppi MV, Núñez C, Lovley DR. 2004. MacA, a diheme c-type cytochrome involved in $\mathrm{Fe}(\mathrm{III})$ reduction by Geobacter sulfurreducens. J Bacteriol 186:4042-4045. https://doi.org/10.1128/JB 186.12.4042-4045.2004.

69. Kim B-C, Lovley DR. 2008. Investigation of direct vs. indirect involvement of the c-type cytochrome MacA in Fe(III) reduction by Geobacter sulfurreducens. FEMS Microbiol Lett 286:39-44. https://doi.org/10.1111/j.1574 -6968.2008.01252.x.

70. Seidel J, Hoffmann M, Ellis KE, Seidel A, Spatzal T, Gerhardt S, Elliott SJ, Einsle O. 2012. MacA is a second cytochrome c peroxidase of Geobacter sulfurreducens. Biochemistry 51:2747-2756. https://doi.org/10.1021/bi300249u.

71. Gennaris A, Ezraty B, Henry C, Agrebi R, Vergnes A, Oheix E, Bos J, Leverrier P, Espinosa L, Szewczyk J, Vertommen D, Iranzo O, Collet J-F, Barras F. 2015. Repairing oxidized proteins in the bacterial envelope using respiratory chain electrons. Nature 528:409-412. https://doi.org/ 10.1038/nature15764.

72. Appel J, Phunpruch S, Steinmüller K, Schulz R. 2000. The bidirectional hydrogenase of Synechocystis sp. PCC 6803 works as an electron valve during photosynthesis. Arch Microbiol 173:333-338.

73. Coppi MV. 2005. The hydrogenases of Geobacter sulfurreducens: a comparative genomic perspective. Microbiology 151:1239-1254. https://doi .org/10.1099/mic.0.27535-0.
74. Qiu Y, Cho B-K, Park YS, Lovley D, Palsson BØ, Zengler K. 2010. Structural and operational complexity of the Geobacter sulfurreducens genome. Genome Res 20:1304-1311. https://doi.org/10.1101/gr.107540.110.

75. Aussignargues C, Giuliani M-C, Infossi P, Lojou E, Guiral M, GiudiciOrticoni M-T, Ilbert M. 2012. Rhodanese functions as sulfur supplier for key enzymes in sulfur energy metabolism. J Biol Chem 287: 19936-19948. https://doi.org/10.1074/jbc.M111.324863.

76. Prat L, Maillard J, Rohrbach-Brandt E, Holliger C. 2012. An unusual tandem-domain rhodanese harbouring two active sites identified in Desulfitobacterium hafniense. FEBS J 279:2754-2767. https://doi.org/10 $.1111 / \mathrm{j} .1742-4658.2012 .08660 . x$.

77. Ravot G, Casalot L, Ollivier B, Loison G, Magot M. 2005. rdIA, a new gene encoding a rhodanese-like protein in Halanaerobium congolense and other thiosulfate-reducing anaerobes. Res Microbiol 156:1031-1038. https://doi.org/10.1016/j.resmic.2005.05.009.

78. Ramírez P, Toledo H, Guiliani N, Jerez CA. 2002. An exported rhodaneselike protein is induced during growth of Acidithiobacillus ferrooxidans in metal sulfides and different sulfur compounds. Appl Environ Microbiol 68:1837-1845. https://doi.org/10.1128/AEM.68.4.1837-1845.2002.

79. Jahan MI, Tobe R, Mihara H. 2018. Characterization of a novel porin-like protein, Extl, from Geobacter sulfurreducens and its implication in the reduction of selenite and tellurite. Int J Mol Sci 19:809. https://doi.org/ 10.3390/ijms19030809.

80. Cutting RS, Coker VS, Fellowes JW, Lloyd JR, Vaughan DJ. 2009. Mineralogical and morphological constraints on the reduction of Fe(III) minerals by Geobacter sulfurreducens. Geochim Cosmochim Acta 73: 4004-4022. https://doi.org/10.1016/j.gca.2009.04.009.

81. Coker VS, Byrne JM, Telling ND, Van Der Laan G, Lloyd JR, Hitchcock AP, Wang J, Pattrick RA. 2012. Characterisation of the dissimilatory reduction of Fe(III)-oxyhydroxide at the microbe-mineral interface: the application of STXM-XMCD. Geobiology 10:347-354. https://doi.org/10.1111/j.1472 $-4669.2012 .00329 . x$.

82. Eusterhues K, Hädrich A, Neidhardt J, Küsel K, Keller TF, Jandt KD, Totsche KU. 2014. Reduction of ferrihydrite with adsorbed and coprecipitated organic matter: microbial reduction by Geobacter bremensis vs. abiotic reduction by Na-dithionite. Biogeosciences 11:4953-4966. https://doi.org/10 .5194/bg-11-4953-2014.

83. Simon R, Priefer U, Pühler A. 1983. A broad host range mobilization system for in vivo genetic engineering: transposon mutagenesis in Gram negative bacteria. Nat Biotechnol 1:784-791. https://doi.org/10.1038/ nbt1183-784.

84. McClure R, Balasubramanian D, Sun Y, Bobrovskyy M, Sumby P, Genco CA, Vanderpool CK, Tjaden B. 2013. Computational analysis of bacterial RNA-Seq data. Nucleic Acids Res 41:e140. https://doi.org/10.1093/nar/ gkt444.

85. Markowitz VM, Chen I-MA, Palaniappan K, Chu K, Szeto E, Grechkin Y, Ratner A, Jacob B, Huang J, Williams P, Huntemann M, Anderson I, Mavromatis K, Ivanova NN, Kyrpides NC. 2012. IMG: the integrated microbial genomes database and comparative analysis system. Nucleic Acids Res 40:D115-D122. https://doi.org/10.1093/nar/gkr1044.

86. Sievers F, Wilm A, Dineen D, Gibson TJ, Karplus K, Li W, Lopez R, McWilliam H, Remmert M, Söding J, Thompson JD, Higgins DG. 2011. Fast, scalable generation of high-quality protein multiple sequence alignments using Clustal Omega. Mol Syst Biol 7:539. https://doi.org/10 $.1038 / \mathrm{msb} .2011 .75$. 